\title{
A mathematical landmark-based method for measuring worn molars in hominoid systematics
}

\author{
Susan J Dykes ${ }^{\text {Corresp., } 1,2}$, Varsha C Pilbrow ${ }^{3}$ \\ ${ }^{1}$ Evolutionary Studies Institute, University of the Witwatersrand, Johannesburg, South Africa \\ 2 School of Geosciences, University of the Witwatersrand, Johannesburg, South Africa \\ 3 Department of Anatomy and Neuroscience, University of Melbourne, Melbourne, Australia \\ Corresponding Author: Susan J Dykes \\ Email address: Sue.Dykes1@outlook.com
}

Worn teeth pose a major limitation to researchers in the fields of extinct and extant hominoid systematics because they lack clearly identifiable anatomical landmarks needed to take measurements on the crown enamel surface and are typically discarded from a study. This is particularly detrimental when sample sizes for some groups are already characteristically low, if there is an imbalance between samples representing populations, sexes or dietary strategies, or if the worn teeth in question are type specimens of fossil species or other key specimens. This study proposes a methodology based predominantly on mathematically-derived landmarks for measuring size and shape features of molars, irrespective of wear. With 110 specimens of lower second molars from five species of extant hominoids (Pan troglodytes, P. paniscus, Gorilla gorilla, G. beringei, Homo sapiens), $\mathrm{n} \geq 20$ per species, $\mathrm{n} \geq 10$ per subspecies, good species separation in morphospace is achieved in a principal components analysis. Classification accuracy in a discriminant function analysis is $96.4 \%$ at the species level and $88.2 \%$ at the subspecies level $(92.7 \%$ and $79.1 \%$, respectively, on cross-validation). The classification accuracy compares favorably to that achieved by anatomically-derived measurements based on published research (94\% and $84 \%$ at the species and subspecies level respectively; $91 \%$ and $76 \%$ on cross-validation). The mathematical landmarking methodology is rapid and uncomplicated. The results support the use of mathematical landmarks to enable the inclusion of worn molar teeth in dental studies so as to maximize sample sizes and restore balance between populations and/or sexes in hominoid systematic studies. 


\section{A mathematical landmark-based method for measuring 2 worn molars in hominoid systematics}

3

4 Susan J. Dykes, ${ }^{1,2}$ Varsha C. Pilbrow ${ }^{3}$

5 'Evolutionary Studies Institute, University of the Witwatersrand, Johannesburg, South Africa

6 2School of Geosciences, University of the Witwatersrand, Johannesburg, South Africa

$7 \quad{ }^{3}$ Department of Anatomy and Neuroscience, University of Melbourne, Victoria 3010 Australia

8

9 Corresponding author

10 Susan J Dykes

11 Sue.Dykes1@outlook.com 


\section{Abstract}

13 Worn teeth pose a major limitation to researchers in the fields of extinct and extant hominoid

14 systematics because they lack clearly identifiable anatomical landmarks needed to take

15 measurements on the crown enamel surface and are typically discarded from a study. This is

16 particularly detrimental when sample sizes for some groups are already characteristically low, if

17 there is an imbalance between samples representing populations, sexes or dietary strategies, or if

18 the worn teeth in question are type specimens of fossil species or other key specimens. This

19 study proposes a methodology based predominantly on mathematically-derived landmarks for

20 measuring size and shape features of molars, irrespective of wear. With 110 specimens of lower

21 second molars from five species of extant hominoids (Pan troglodytes, P. paniscus, Gorilla

22 gorilla, G. beringei, Homo sapiens), $\mathrm{n} \geq 20$ per species, $\mathrm{n} \geq 10$ per subspecies, good species

23 separation in morphospace is achieved in a principal components analysis. Classification

24 accuracy in a discriminant function analysis is $96.4 \%$ at the species level and $88.2 \%$ at the

25 subspecies level (92.7\% and 79.1\%, respectively, on cross-validation). The classification

26 accuracy compares favorably to that achieved by anatomically-derived measurements based on

27 published research (94\% and 84\% at the species and subspecies level respectively; $91 \%$ and $76 \%$

28 on cross-validation). The mathematical landmarking methodology is rapid and uncomplicated.

29 The results support the use of mathematical landmarks to enable the inclusion of worn molar

30 teeth in dental studies so as to maximize sample sizes and restore balance between populations

31 and/or sexes in hominoid systematic studies.

\section{Introduction}


35 Studies into the population systematics of extant hominoids are of great significance to

36 primatologists, anthropologists and paleoanthropologists alike. Primatologists utilize such studies

37 of diversity to obtain a better understanding of the natural history of the hominoids and promote

38 conservation of endangered groups (for example, Wolfheim, 1983; Oates, 1996; Butynski, 2003;

39 Kalpers et al., 2003; Kormos et al., 2003; Taylor and Goldsmith, 2003; Bergl, 2006; Oates et al.,

40 2007; Williamson \& Fawcett, 2008; Plumptre et al., 2010; Junker et al., 2012; Nater et al., 2017).

41 Anthropologists and paleoanthropologists study species-subspecies diversity to provide

42 analogues upon which to base conclusions regarding alpha taxonomy and the naming of new

43 species in the fossil hominin context (Vitzthum, 1984; Ferguson, 1989; Wood et al., 1991;

44 Uchida, 1992, 1996; Albrecht \& Miller, 1993; Shea et al., 1993; Richmond \& Jungers, 1995;

45 Braga, 1995; Plavcan \& Cope, 2001; Albrecht et al., 2003; Pilbrow, 2003; Braun et al., 2004;

46 Mitteroecker et al., 2004; Scott \& Lockwood, 2004; Lee, 2005; Baab, 2008; Lordkipanidze et al.,

47 2013). Extant hominoid species that are closely related to extinct hominin species are considered

48 to be valuable proxies or analogues of morphological variability in fossil hominin species

49 (Kimbel \& Martin, 1993; Ackermann, 2003).

50 An understanding of variability within and between species and subspecies in extant

51 hominoid groups is therefore key to predicting how much variability to expect within and

52 between fossil hominin species. As sample sizes for fossil hominin skeletal elements are limited,

53 many studies focus on teeth, which are the most abundantly-represented skeletal element in the

54 fossil record due to the excellent preservation qualities of the outer enamel surface (OES). Apart

55 from the fact that teeth are likened to preformed "fossils" (Boyde, 1997, p. 29), in that, once

56 erupted, they do not change size or shape during the individual's lifetime, making them a useful 
57 resource for morphometric analyses, their value is enhanced by the fact that large samples of

58 teeth with good provenance and sex data are available in museums.

Unworn or minimally worn teeth lend themselves to many different types of three-

60 dimensional (3D) and two-dimensional (2D) analyses. Micro-computerized tomography scans of

61 teeth allow for 3D studies to be carried out into the enamel-dentine junction (EDJ), which

62 preserves in pristine form the underlying morphology of the dentine. The EDJ provides sufficient

63 information with which to differentiate between species (Skinner et al., 2008, 2009; Braga et al.,

64 2010; Crevecoeur et al., 2014). The sharpness of the ridges running between the dentine horns

65 provides secure and repeatable landmarking sites (Skinner et al., 2009). Nevertheless, the EDJ

66 proves difficult to landmark once wear has progressed through the enamel obliterating the

67 dentine horns. In such situations the dentine peaks either need to be inferred or such specimens

68 are typically not selected for CT scanning. Some further challenges for 3D studies of teeth

69 include the high cost of scanning, difficulties in segmenting enamel from dentine in highly

70 fossilized teeth, and the time involved in segmenting dental tissues from image stacks.

The use of 2D imagery still remains attractive, as geographically-comprehensive

72 collections of images may be obtained relatively swiftly and cost-effectively from museums around the world and amalgamated into manageable databases. Shape and size analyses of the morphology of the OES, as studied from occlusal-view photographs of molars, have been successful in discriminating between extant great ape species, subspecies and even populations (Pilbrow, 2003, 2006, 2010; Uchida, 1998a, b; Singleton et al., 2011). This type of image has proven equally useful for fossil hominin taxonomic studies (e.g. Wood et al. 1983; Wood and Abbott, 1983; Suwa et al., 1994, 1996; Suwa, 1996; Bailey, 2004; Martinón-Torres et al., 2006; 
80 quick, accurate and cost effective. However, once past the first stages of wear, anatomical

81 landmarks such as cusp tips, crests, and foveae are either difficult to identify or are obliterated

82 from view completely. The researcher usually discards such specimens, resulting in reductions in

83 sample sizes (see also Stojanowski and Johnson, 2015). This is problematic in cases where the

84 specimens are holotypes or paratypes of fossil species and should warrant inclusion, or where

85 fossil sample sizes are generally low, or there is an imbalance between specimens representing

86 males and females, geographical regions or dietary strategies.

The purpose of this paper is to propose a method for including worn molar crowns in taxonomic studies by capitalizing on the few anatomical landmarks that remain discernible even after considerable wear. These anatomical landmarks, which are classified as Type I (Bookstein, 1991), are sited at the grooves separating the main cusps at the perimeter of the molar crown.

91 The grooves are usually visible despite high levels of wear on the enamel surface. We start with

92 these Type I landmarks and thereafter use mathematically-derived Type III landmarks

93 (Bookstein, 1991) at strategic points on and around the crown. Thereafter, landmarks are used to

94 calculate linear and angular measurements, which provide detailed information on the shape of

95 the tooth and serve as the raw data for further analyses. We test the hypothesis that

96 measurements obtained from mathematically-derived landmarks provide at least as good

97 discrimination between chimpanzee, gorilla and human molars as obtained from anatomically-

98 derived landmarks in 2D and 3D studies. We use lower second molars in this study, but the

99 methodology is applicable to other molar types. 


\section{Materials}

104 We selected 110 occlusal-view 2D images of lower second molars (LM2) to represent five

105 species (eight subspecies) of extant hominoids: Gorilla beringei beringei $(\mathrm{n}=10)$, G. b. graueri

$106(\mathrm{n}=10)$, G. gorilla gorilla $(\mathrm{n}=20)$, Pan troglodytes verus $(\mathrm{n}=10), P$. t. troglodytes $(\mathrm{n}=10), P$.

107 t. schweinfurthii $(\mathrm{n}=10)$, P. paniscus $(\mathrm{n}=20)$ and modern Homo sapiens $(\mathrm{n}=20$, of which 8

108 were selected to represent hunter-gatherer groups and 12 to represent groups with other

109 subsistence strategies). The photographs relating to Pan and Gorilla were randomly selected

110 from the images used by Pilbrow (2003, 2006, 2007, 2010), and those relating to Homo sapiens

111 were randomly selected from the images used by Dykes (2018). The selected samples were

112 equally balanced between males and females to ensure that variation from sexual dimorphism

113 was represented and chosen from geographically-diverse populations to represent inter-

114 population variation. All teeth included in this study come from previous studies and were at

115 minimal stages of wear, with either no dentine exposed, dentine exposed as points on cusp tips,

116 or dentine exposed as small pits on cusp tips (Pilbrow, 2003). The reason for utilizing relatively

117 unworn teeth in this study is to allow for the methodology to be compared for accuracy with

118 existing methodologies, which are reliant on identifying anatomical landmarks. Nevertheless, it

119 is important to reiterate that the landmarking method presented here remains valid for both worn

120 and unworn teeth, because the landmarks atop the surface of the enamel are calculated

121 identically, whether or not occlusal surface features still remain visible. This holds true of most

122 stages of advanced tooth wear, provided that the perimeter wall (the occlusal outline in each

123 image) is still intact with cusp intersections along the perimeter edge visible. A list of images

124 used is summarized in Table 1.

$125<$ Insert Table 1 here $>$ 


\section{Image processing}

128 All photographs were taken by the authors, using identical methodology, as described in Bailey

129 et al. (2004), Pilbrow (2006, 2010) and Dykes (2014, 2018). Images were then processed using

130 GIMP ${ }^{\circledR}$ (the freeware equivalent of Adobe Photoshop ${ }^{\circledR}$ ) as left-side teeth (right-side teeth were

131 mirrored if necessary, in keeping with other concurrent research projects) with the mesial side of

132 the tooth to the left of the image, the distal side to the right, the lingual side to the top of the

133 image and the buccal side to the bottom. The mesial edge and the mesiodistal groove of the tooth

134 in normal rotation (Goose, 1963) provides a guideline for the longitudinal axis of the tooth

135 (Wood, 1991; Benazzi et al., 2012), and this is oriented horizontally on screen. Corrections of

136 any interstitial wear or slight damage to the perimeter outline of the tooth are carried out digitally

137 in Adobe Illustrator ${ }^{\circledR}$ following the methodology of Wood and Abbott (1983). Thereafter, the

138 rectangle tool was used to superimpose a bounding box around the perimeter of the molar, to

139 stand proxy for the corrected mesiodistal (MD) and maximum buccolingual diameter (BL)

140 measurements, the latter being at right angles to the MD diameter (Wood and Abbott, 1983). The

141 bounding box can be seen in Figure 1.

142

\section{Landmarking}

144 In total, 29 landmarks were chosen to represent the general dimensions, key points around the

145 occlusal perimeter and the cusp arrangements of the tooth. The landmarks are depicted in Figure

1461 and described in Table 2. These landmarks also allowed for easily-interpretable wireframes to

147 be produced for the analysis of relative warps in a Principal Components Analysis (PCA), and to

148 characterize consensus molar shapes of the groups. Measurements taken between landmarks were

149 also adaptable for further discriminant function and other statistical analyses. The first landmark 
150 (1) was placed at the geometric center of the tooth as calculated from the bounding box. Four

151 further landmarks $(2,3,4,5)$ were placed around the perimeter of the box to mark the corrected

152 mesiodistal and the maximum buccolingual diameter of the tooth. The next five landmarks $(6,7$,

$1538,9,10)$ are Type I anatomical landmarks positioned at the points where the grooves between the

154 cusps intersect with the perimeter of the tooth. These are the only Type I landmarks used in this

155 study. Five additional landmarks $(11,12,13,14,15)$ were placed at the midpoints of the lines

156 connecting the anatomical landmarks, $6-10$. These helped to provide a general orientation of each

157 cusp. The next five landmarks $(16,17,18,19,20)$ were placed at the edge of the crown to mark

158 the center point of each cusp arc around the perimeter. These were identified by drawing straight

159 lines from the bounding box center (from landmark 1) to the edge of the crown while bisecting the

160 lines connecting the Type I landmarks. Thus, a line from the center passed through landmark points

$16111-15$ to reach the perimeter of the crown and provide a landmark point. The midpoints of the

162 lines from landmark 1 to the peripheral landmarks $16-20$ themselves formed an additional five

163 landmarks $(21-25)$, which were used to stand proxy as the mathematical center of each cusp.

164 Finally, the mathematically-derived centers of the mesial and distal cusps, respectively, metaconid

165 and protoconid, and entoconid and hypoconid, were used in extending lines towards the lingual

166 and buccal edge of the crown and provide additional four peripheral landmarks $(26-29)$. These

167 helped to provide an orientation of the mesial and distal cusps relative to the longitudinal axis of

168 the crown. In all, 14 landmarks were used to provide a wireframe outline shape of the tooth: five

169 pinpointing the cusp intersections, five marking the mathematically-derived centers of each cusp

170 arc and four locating the orientations of the mesial and distal cusps relative to the longitudinal

171 orientation of the crown. Features on the surface of the crown were captured in wireframes by two

172 polygons: an outer polygon joining the five cusp intersections at the periphery, and an inner 
173 polygon formed by the five mathematical midpoints of each cusp. Landmark 1 is identified in the

174 wireframe via the inclusion of the MD and BL diameters, which intersect at the center of the tooth

175 in the occlusal basin of the tooth.

176 Landmarking was carried out using Image ${ }^{\circledR}$ freeware, which has the capacity to scale

177 images and which has a line segment tool that shows the midpoint of lines traced onto the image

178 and a "blob" tool to mark these midpoints with a colored dot. The landmark placement tool outputs

179 the $\mathrm{x}$ and $\mathrm{y}$ coordinates of landmarks after they have been sited, ready for export to any spreadsheet

180 software such as Microsoft Excel®, which may be prepopulated with formulae to calculate

181 distances and angles between landmarks. The whole process of scaling, marking midpoints and

182 landmarking each tooth takes on average three to four minutes to complete.

183

$184<$ Insert Figure 1 here $>$

185

186 Figure 1. Landmarks sited on a Pan troglodytes lower second molar (RG, Tervuren, \#29075)

$188<$ Insert Table 2 here>

189

190 Special landmarking cases - molar crowns with four or six cusps.

191 All molars in a landmark-based analysis require the same number of landmarks per specimen.

192 For teeth with four cusps, for instance in certain individuals of modern $H$. sapiens, a

193 modification is made to the landmarks pertaining to the absent hypoconulid (landmarks 13,18

194 and 23). In this situation a hypoconulid is inferred from the small groove separating the

195 entoconid and hypoconid (Fig. 2). Landmarks are sited on this small inter-cusp area as though it

196 were a normal hypoconulid. 
$198<$ Insert Figure 2 here>

199

200 Figure 2. Landmarks on H. sapiens LM2 with four cusps.

201

202 In the case of a lower molar with six cusps (C6 or tuberculum sextum), the C6 is bisected

203 between the entoconid and hypoconulid for purposes of marking the intersection between these

204 cusps (Wood, 1991, p. 306, Fig. 8.13[j]). This allows the same number of landmarks to be

205 maintained across specimens (Fig. 3).

206

$207<$ Insert Figure 3 here>

Figure 3. Homo sapiens LM2 with six cusps.

\section{Intra-observer and inter-observer errors}

211 Intra- and inter-observer errors were measured for tilt of molars at the image-capturing stage and

212 orientation of the on-screen image at the image-processing stage. To quantify intra-observer

213 errors of tilt, Amira ${ }^{\circledR}$ software was used to analyze differences in tilt angles of the occlusal

214 surface in the $\mathrm{x}, \mathrm{y}$ and $\mathrm{z}$ planes of three different images of the same tooth, all taken on separate

215 occasions. The maximum difference in tilt between these images was 0.014 degrees along the $\mathrm{x}$

216 plane, 0.107 degrees along the y plane and 0.098 degrees along the $\mathrm{z}$ plane. To calculate the

217 effect of such errors of tilt, landmarks were placed on the surface of a 3D image of a pristine

218 tooth and Amira ${ }^{\circledR}$ software was used to measure landmark coordinate changes at various degrees

219 of tilt across the buccolingual axis (the y plane, where tilt is most likely to occur during the

220 photographic process). It was found that an error of tilt at 2 degrees would affect the landmark

221 coordinate placements by $1 \%$ over the length of the buccolingual axis. Inter-observer error in the

222 longitudinal rotation of molars during the image-processing stage was evaluated by two 
223 observers using five teeth randomly selected from five different species over a period of

224 approximately six months. Landmarks were placed on each image and the mean deviations

225 between these coordinates were calculated. The average deviation measured against the length of

226 the mesiodistal axis was $0.295 \%$, and the average deviation measured against length of the

227 buccolingual axis was $0.316 \%$.

228

229 Principal Component Analysis (PCA)

230 After translation, rotation and scaling of the images via a Generalized Procrustes Analysis

231 (GPA), two types of principal component analyses were conducted in Morphologika ${ }^{\circledR}$ :

232 traditional shape-only or shapespace PCA and size-versus-shape or formspace PCA

233 (Mitteroecker et al., 2004). This latter PCA adds the natural logarithm of the centroid size for

234 each specimen as a variable in the analysis and the resultant plot shows predominantly size

235 variation along the first principal component, with the smallest specimens grouping at the

236 negative end of the axis and the largest specimens at the positive end. A formspace PCA is

237 particularly useful in taxonomic analyses with molars, because tooth size, which remains

238 unchanged after the tooth has erupted, can be an important diagnostic feature in interspecific and

239 intraspecific analyses. Morphologika ${ }^{\circledR}$ also calculates wireframes (or point clouds) and a slider

240 bar allows these wireframes to be shown as relative warps along the $\mathrm{x}$ and $\mathrm{y}$ axes, for immediate

241 visualization of shape changes along each principal component axis. These relative warps

242 wireframes provide useful interpretation of PCA plots.

243

244 Discriminant function analyses (DFA)

245 The same sample of 110 hominoid lower second molars was analyzed by means of stepwise

246 discriminant function analyses (DFA) in SPSS ${ }^{\circledR}$, with leave-one-out cross-validation. A DFA 
247 minimizes within-group variation and maximizes between-group variation, providing good

248 understanding of relative separation among the groups being analyzed. In a stepwise DFA,

249 variables are included in the analysis until they no longer provide any further significant

250 discrimination between groups, at which point redundant variables are removed from the

251 analysis (Manly, 2005). Euclidean coordinates of landmarks are used to derive measurements for

252 the DFA. Depending on the analysis and the sample sizes, these can include the natural $\log$ of

253 centroid size as a proxy for overall tooth size, linear dimensions of the tooth crown, orientation

254 of occlusal features measured in radians of angles, and shape features measured as ratios

255 between landmarks, as shown in Figure 4. For the present analysis, as the minimum sample size

256 per group was 10 individuals, nine measurements that provided the highest canonical loadings

257 were selected for the DFA. These are described in Table 3.

\section{Testing the accuracy of the methodology against traditional (anatomically-based)} methodologies

261 Stepwise DFA with leave-one-out cross-validation was also used to test whether mathematically-

262 derived measurements would produce the same level of classification accuracy as anatomically-

263 derived measurements. To do this, we used the same 110 specimens chosen for the other

264 analyses, to provide identically-matched samples. Anatomically-derived measurements from

265 previous publications (Pilbrow, 2006, 2010) were selected for the 90 chimpanzee and gorilla

266 LM2s used in this study. The 20 human LM2 anatomical measurements were taken anew using

267 the same molar images as this study. As the sample sizes per group in this study are smaller than

268 in the previously published studies, a smaller set of independent variables were selected for the

269 stepwise DFA to ensure that we met the assumptions of a robust DFA. The following nine

270 variables that provided the highest canonical loadings were selected: length of crown, breadth of 
271 crown measured at mesial and distal cusps, distance between mesial and distal cusps, orientation

272 of buccal and lingual cusps, and orientation of hypoconulid and cristid obliqua (Pilbrow, 2006).

273 In a further comparison of the classification accuracy of mathematical landmarks with

274 anatomical landmarks, a random sample of 25 specimens was chosen, simulating the species-

275 subspecies groups used in a study by Skinner et al. (2009) on discriminating species and

276 subspecies of Pan using EDJ morphology. Thus, specimens of $P$. t. troglodytes, $P$. t. verus and $P$.

277 paniscus were selected. Classification accuracy was computed using the same nine

278 mathematically-derived variables as described above and compared with the results from Skinner

279 et al. (2009). Bivariate plots along the first two discriminant functions were also compared for

280 grouping patterns.

281

$282<$ Insert Figure 4 here $>$

283

284 Figure 4. Raw distances (A) and angles (B) for use in DFA analyses.

285

$286<$ Insert Table 3 here $>$

287

288

\section{Results}

289

290

\section{Principal components analyses}

291

The first two principal components in the shapespace (shape only) analysis are shown in

292 Figure 5. Relative warps wireframes at the ends of each axis show the average molar shape

293 change along that axis.

294

$295<$ Insert Figure 5 here $>$ 
297 Figure 5. Principal components analysis in shapespace (shape only) of 5 extant hominoid 298 species. Legend: open circles $=$ Gorilla gorilla ; closed diamonds $=G$. b. beringei; X-crosses $=$ 299 G. b. graueri; $\mathrm{T}=$ Pan troglodytes troglodytes; $\mathrm{S}=P$. $t$. schweinfurthii; $\mathrm{V}=P$. $t$. verus; Targets $300=P$. paniscus; Stars $=H$. sapiens. Red symbols denote females, blue symbols denote males. All 301 wireframes depict molars with the mesial edge to the left, the distal edge to the right, the lingual 302 303

304 Pan, H. sapiens and Gorilla separate well in morphospace, but species and subspecies of Pan 305 overlap with each other, as do species and subspecies of Gorilla. PC1 accounts for $66.1 \%$ of

306 variance and relative warps wireframes indicate that broad teeth with distally-oriented

307 hypoconulids and buccodistally-oriented hypoconids group towards the negative end of the $\mathrm{x}$ 308 axis (Pan and H. sapiens), while relatively narrow teeth with buccodistally-oriented

309 hypoconulids and buccally-oriented hypoconids (Gorilla) group towards the positive end. PC2

310 (y-axis) accounts for $11.6 \%$ of variance, with broad molars, having reduced or absent

311 hypoconulids, grouping towards the negative end of the axis (certain H. sapiens molars), and

312 narrow molars with larger, well-defined hypoconulids grouping towards the positive end of the

313 axis. Most Pan molars plot above the x-axis, with the exception of a few P. t. verus molars that

314 are slightly broader across the crown and plot below the x-axis. Separation in morphospace is

315 therefore good at the level of genus, but lacking at the species and subspecies level. There is also

316 no separation in shapespace between molars belonging to male and female gorillas, indicating

317 that in the absence of a size component, there is little to determine sexual dimorphism in shape 318 alone. 
322 Figure 6. Principal components analysis in formspace (shape-versus-size) of 5 extant hominoid

323 species. Legend: open circles $=$ Gorilla gorilla; closed diamonds $=G$. $b$. beringei; X-crosses $=$ 324 G. b. graueri; $\mathrm{T}=$ Pan troglodytes troglodytes; $\mathrm{S}=P$. $t$. schweinfurthii; $\mathrm{V}=P$. $t$. verus; Targets $325=$ P. paniscus; Stars $=H$. sapiens. Red symbols denote females, blue symbols denote males. All 326 wireframes depict molars with the mesial edge to the left, the distal edge to the right, the lingual 327 328

In the size-versus-shape (formspace) analysis (Fig. 6), with size added back as a variable, small molars group towards the negative end of the $\mathrm{x}$-axis and large molars group towards the positive end (PC1). This first component accounts for $93.1 \%$ of variance and PC2 (y-axis) accounts for $2.3 \%$ of variance. In formspace, $P$. troglodytes, $P$. paniscus and $H$. sapiens now separate well and can be differentiated spatially. Species and subspecies of Gorilla still overlap with each other, but not as much as in the shape-only PCA. The molars of G. b. graueri group as generally larger than molars of $G$. $b$. beringei, which in turn group as generally larger than those of $G$. gorilla. Males with larger molars tend to group at more positive values along the axis, although the separation between males and females is most discernable in the sexually dimorphic gorillas. Along PC2 (the y-axis), Gorilla species mostly plot above the axis (narrower teeth) with a few molars grouping just below the x-axis (slightly broader across the crown). Examining the plot

340 and the wireframes, small, relatively narrow molars with pronounced hypoconulids group in the

341 top left quadrant of the graph, with Pan paniscus well separated to the top left-hand side of the

342 plot, being the smallest molars in the sample. Pan troglodytes molars generally group in this

343 quadrant as well, particularly those belonging to P. t. troglodytes and P. t. schweinfurthii, which

344 show considerable overlap. In the bottom left quadrant, relating to molars that are progressively broader across the crown, H. sapiens is generally separated from the few P. troglodytes molars notably those belonging to $P$. $t$. verus, which are generally relatively broader across the crown than are specimens from the other two Pan subspecies. In addition to the relative broadness of 
348 the crowns, the hypoconulid becomes less pronounced in the individuals grouping towards

349 negative values of PC2.

350

351 DFA Classification accuracy, 110 LM2s from five species / eight subspecies

352 Stepwise discriminant function analyses showed that classification accuracy at the species level

353 was $96.4 \%$ (Table 4). Classification accuracy for individual groups were as follows: G. beringei

354 (90\%); G. gorilla (95\%); P. troglodytes (96.7\%), P. paniscus (100\%) and H. sapiens (100\%).

355 Two of the twenty G. beringei specimens classified with G. gorilla, with one G. gorilla

356 reciprocally classifying with $G$. beringei. Within Pan, one P. troglodytes $(\mathrm{n}=30)$ was grouped

357 with $P$. paniscus. On cross validation, one further G. gorilla and G. beringei molar each

358 classified reciprocally, one $P$. paniscus specimen grouped with $P$. troglodytes and one $H$. sapiens

359 molar classified with $P$. paniscus, bringing the cross-validated classification accuracy to $92.7 \%$.

360 The coefficients most influencing the analysis along Function 1, which accounted for $91.9 \%$ of

361 variance, were the buccolingual groove measurement (negatively loaded) and the distal cusp

362 measurement (positively loaded). Other loadings contributing to discrimination between groups

363 along Function 1 were the breadth measurement across the mesial cusps (positively loaded), the

364 distal edge of the buccal development groove (negatively loaded), the mesiodistal measurement,

365 and the angle of the mesial cusps (negatively loaded): this angle is juxtaposed against the angle

366 of the distal cusps, which is positively loaded. Size, particularly breadth across the tooth, is

367 therefore the main discriminating feature at the species level, but it is noted that the relationship

368 between the mesial cusps and the distal cusps plays a major role (linear measurements and angles

369 between the two sides, and the distance of the distal cusps from the buccal side of the

370 buccolingual groove). Along Function 2, which accounted for a further $6.6 \%$ of variance,

371 discriminating factors include the breadth measurement along the buccolingual groove, the ratio 
372 of the curvature of the hypoconulid in relation to its length from the tooth center, followed by the

373 breadth of the mesial cusps.

374 At the subspecies level (Table 5), 88.2\% of the specimens were classified according to

375 their predicted groups (79.1\% on cross-validation), ranging at the group level from $70 \%$ to

$376100 \%$. In this instance, there was some reciprocal misclassification in the original data between

377 the three Gorilla subspecies, as well as between P. t. troglodytes subspecies, particularly

378 between the central and eastern chimpanzees (P. t. troglodytes and P. t. schweinfurthii). One $P$.

379 paniscus specimen classified with the P. t. troglodytes group. All H. sapiens molars classified

380 correctly to the predicted group. On cross-validation, there was additional misclassification

381 between G. b. beringei and G. b. graueri, but G. g. gorilla molars classified as before. Within

382 Pan, $P$. t. verus and $P$. paniscus grouped as before, but there was further misclassification

383 between P. t. troglodytes and P. t. schweinfurthii. Homo sapiens saw two molars classifying with

384 the molars of P. t. verus (generally broader across the crown than the other subspecies) and one

385 with P.t. troglodytes.

386 At the subspecies level, Function 1 accounted for $89.6 \%$ of variance and Function $2,8 \%$.

387 Tooth size is the main discriminating feature, particularly relative breadth, with the relationship

388 between the measurement across the buccolingual groove (negatively weighted along Function

389 1) and the measurement across the distal cusps (positively weighted along Function 1) playing a

390 key role in discriminating between groups. Tables 4 and 5 present the classification accuracy of

391 the 110 lower second molars at the species and subspecies levels.

$392<$ Insert Table 4 here>

$393<$ Insert Table 5 here>

394 
395 Comparison of methods \#1: DFA classification accuracy of mathematically-derived 396 measurements versus anatomically-derived measurements, based on Pilbrow (2006)

397

398 The classification results at the species level, based on 110 specimens using variables derived

399 from anatomically-based landmarks, are shown in Table 6. Classification accuracy ranges from

$40085 \%$ for G. gorilla and G. beringei, to $95 \%$ for $P$. paniscus, and $100 \%$ for P. troglodytes and $H$.

401 sapiens. The overall classification accuracy is $94 \%$, with cross-validation accuracy being $91 \%$.

402 Misclassified specimens of $G$. gorilla and G. beringei are reciprocally classified, and a single

403 misclassified specimen of $P$. paniscus falls in H. sapiens.

At the subspecies level classification accuracy ranges from $50 \%$ for G. g. beringei, and $60 \%$ for $P$. t. schweinfurthii to $100 \%$ for $P$. t. verus and $H$. sapiens. The overall classification accuracy for subspecies is $84 \%$, with a cross-validation accuracy of $76 \%$ (Table 7 ). Misclassified

407 specimens are assigned to subspecies within the species, except for a single misclassified 408 specimen of $P$. paniscus, which is assigned to $H$. sapiens.

409 Tooth size is the main discriminating feature at the species and subspecies level. In both 410 analyses, discriminant function one accounts for $89 \%$ of the overall variance and is heavily

411 loaded by length and breadth dimensions and distance between cusps.

$412<$ Insert Table 6 here>

$413<$ Insert Table 7 here $>$

415 Comparison of methods \#2: Mathematically-derived versus anatomically-derived DFA 416 output based on Skinner et al. (2009)

417 The average classification accuracy of a DFA for a randomly-drawn sample of 25 specimens of 418 P. t. troglodytes, $P$. t. verus and P. t. schweinfurthii using mathematically-derived measurements 419 was $100 \%$ (original and cross-validated classification accuracy). This matches the 100\% 
420 classification accuracy for 25 lower second molars reported by Skinner et al. (2009), based on a

421 study of the EDJ of these teeth. The spatial groupings of the three species/subspecies output from

422 the mathematically-derived DFAs (Fig. 7) closely match the groupings shown by Skinner et al.

423 (2009).

424

$425<$ Insert Figure 7 here $>$

426 Figure 7. Convex hull plots of sample of 25 specimens chosen to match the species-subspecies 427 groups used by Skinner et al. (2009).

428

\section{Discussion}

430

431 In the context of fossil hominin taxonomic studies, molars play an important role as these are the 432 most abundantly preserved element in fossil assemblages and are well represented in museum 433 and academic collections. However, many of these teeth are heavily worn or damaged on the 434 crown, and researchers are usually forced to reduce limited samples of fossil specimens even 435 further by discarding specimens without easily-identifiable anatomical features on the crown 436 enamel. Some researchers have suggested approximating cusp peaks from the shapes of wear 437 facets (Martinón-Torres et al., 2006), but this results in an analysis with a mixture of approaches 438 to cusp-peak location.

439 Benazzi et al. $(2011 ; 2012)$ have successfully avoided having to locate cusp tips on worn

440 teeth, and have shown good taxonomic discrimination between worn Neanderthal and modern

441 human teeth, using cervical crown outlines and occlusal crown outlines, which are still present in

442 worn teeth. The present study differs from these studies, firstly in that 3D images are not

443 required for the determination of cervical crown outlines: the surface enamel crown outline

444 visible from 2D images is sufficient for the calculation of all landmarks used in this study, 
445 provided that the points where the grooves between cusps meet the outline shape are visible (or

446 readily inferable) in the images used. This would include worn teeth up to and including wear

447 stage 7 as defined by Smith (1984), wherein dentin is exposed on the entire molar crown surface,

448 but the enamel rim remains largely intact; but not late wear stage 7 and wear stage 8 , where the

449 enamel rim is severely broken down. A second difference is that by using midlines between

450 cusp grooves and midpoints to stand proxy for the mathematical centers of each cusp, rather than

451 semi-sliding landmarks around the outline (Bookstein, 1996/7), it becomes possible to calculate

452 the relative orientations of cusps through these cusp centers, both in relation to each other and to

453 the longitudinal axis of the tooth. This study capitalizes on the fact that linear measurements and

454 cusp angles, which have proven to be diagnostic measurements for taxonomic studies (e.g.

455 Pilbrow, 2006, 2007, 2010), are readily calculated from the landmarks located both around the

456 perimeter and on the surface itself. Over and above analyses based on Euclidean coordinates of

457 landmarks (GPA, PCA and EDMA - Euclidean Distance Matrix Analysis), this methodology

458 allows for other types of analyses to be carried out that make use of raw measurements,

459 including DFA, CV (coefficients of variation) analyses and other types of odontometric studies.

460 The results of analyses based on these mathematically-derived measurements would then be

461 useful for comparison with existing studies.

462 The aim of the study was to establish whether mathematically-sited landmarks and the

463 raw measurements derived from these, based on the occlusal crown outline of lower second

464 molars, which is intact in both unworn and worn teeth, would lead to good separation in

465 morphospace and high classification accuracy levels in a DFA. Further to this, the results should

466 be at least equivalent in accuracy to the results achieved by other researchers. DFA classification 
467 accuracy outputs were compared to those achieved in two existing studies (modified from

468 Pilbrow, 2006 and Skinner et al., 2009).

469

470 PCA separation in morphospace and DFA classification accuracy

471 The results of the geometric morphometric and discriminant function analyses on 110 lower

472 second molars of five species of extant hominoid ( $\mathrm{n} \geq 10$ per subspecies) show good success in

473 group separation, with $96.4 \%$ classification accuracy at the species level and $88.2 \%$ classification

474 accuracy at the subspecies level. Specimens visualized on shape-only (shapespace) and size-and-

475 shape (formspace) PCA plots grouped according to morphological differences that are diagnostic

476 for each species and genus. Shape differences were observed between Gorilla, Pan and Homo

477 sapiens at the genus level in the shape-only analysis, but as expected in a shapespace plot, there

478 was no sexual dimorphism evident between molars belonging to male and female gorillas, and

479 no interspecific general shape differences between $P$. paniscus and P. troglodytes (Singleton et

480 al., 2011), with the exception of specimens of $P$. $t$. verus, which are on average relatively wider

481 across the crown than other subspecies (Uchida, 1996; Pilbrow, 2006; Dykes, 2018). There was

482 some overlap between $P$. t. troglodytes and $P$. t. schweinfurthii molars in shape space, which is

483 to be expected as these two subspecies interbred until relatively recently (Hey, 2010, Gonder et

484 al., 2011). Shape variation in $H$. sapiens lower second molars exceeded that of other species,

485 undoubtedly a factor of differential evolution in molar cusp simplification (reduction in size, or

486 absence of a hypoconulid), due to regional differences in basic subsistence strategies of hunter-

487 gatherers and agriculturalists over many millennia (Bailit and Friedlaender, 1996; Brace and

488 Mahler, 1971; Sofaer, 1973; Brace et al., 1987; Corruccini et al., 1983; Corruccini, 1984; Larsen,

489 1995; Dempsey and Townsend, 2001; Grine, 2002, 2005; Brown and Maeda, 2004; Pinhasi et

490 al., 2008; Emes et al., 2011; Hodder, 2017; Ungar, 2017, Dykes, 2018). This unique shape 
491 variation in modern $H$. sapiens will be examined in detail in a further study, based on larger

492 sample sizes.

493 When size is added to the analysis, there is excellent spatial separation at the species level

494 on a PCA formspace plot. Gorilla molars were reasonably separated between the two species

495 represented, with sexual dimorphism being observed between molars belonging to males and

496 females at the species and subspecies level. Eastern lowland gorillas, G. b. graueri, have the

497 largest body size of all gorillas (Jungers and Susman, 1984), and this is reflected in the grouping

498 of their molars, towards the positive extreme of the x-axis in the plot. Western lowland gorillas,

499 G. g. gorilla, grouped at lower values along the x-axis, with only two male specimens

500 overlapping with males of the Eastern mountain gorillas, G. b. beringei. Gorilla gorilla as a

501 species showed more shape variability along PC2 in their lower second molars than G. beringei,

502 with some molars that are relatively narrow buccolingually belonging both to males and females

503 grouping at higher values along the $\mathrm{y}$-axis. On the other extreme of the $\mathrm{x}$-axis, $P$. paniscus

504 grouped cohesively in the top left-hand quadrant, having the smallest molars that are generally

505 relatively narrow. Most $P$. troglodytes molars grouped above the x-axis, in a similar range along

506 PC2 as that observed for Gorilla species with relatively narrow molars; however, the broader

507 molars of P. t. verus fell below the $\mathrm{x}$-axis, in the quadrant occupied by H. sapiens molars.

508 Overall, groupings in morphospace followed expected patterns of molar shape and size

509 differences between genera, species, subspecies, sexes and subsistence strategies.

510 Comparing the PCA and DFA results, it can be seen that in both the shape-only

511 (shapespace) and the shape-and-size (formspace) PCA analyses, there are similarities between

512 the factors affecting the first two principal components of the PCAs on the one hand, and the

513 factors accounting for the main canonical loadings along the first two functions of the DFAs on 
514 the other. The relative warps of the wireframes traced from the negative to the positive end of the

515 axes of the PCA plots show a shape change between relative breadth of tooth (both axes), the

516 extent of the buccal development groove (x-axis), the amount of curvature of the hypoconulid (y-

517 axis), and along both axes, a change in the relative dimensions (raw measurements and

518 orientations) between the distal cusps and other breadth and length variables. While size is

519 shown to be an important discriminating factor between groups, relative dimensions and angles

520 between variables therefore also play significant diagnostic roles. The methodology of

521 landmarking worn teeth discussed in this paper makes provision for landmarks to be placed not

522 only at selected inflexion points around the outline of the tooth but also on the enamel surface

523 itself, irrespective of how worn that might be, thus providing for the inclusion of key cusp-

524 related data (dimensions and angles) into the analysis that would otherwise be lost, if only

525 perimeter-shape landmarks are to be used.

526

527 Comparisons of accuracy between mathematically-derived measurements and 528 anatomically-derived measurements

529 Mathematically-derived measurements compare well with anatomically-derived measurements

530 in both comparative analyses, based on classification accuracy outputs from stepwise DFAs. In

531 the first analysis of 110 specimens from five species and eight subspecies, using only nine

532 variables, the mathematically-derived measurements produced a classification accuracy of $96.4 \%$

533 at the species level and $88.2 \%$ at the subspecies level, versus $93.6 \%$ at the species level and

$53483.6 \%$ at the subspecies level for the anatomically-derived measurements taken from the same

535110 teeth. In the second analysis of 25 specimens from $P . t$ troglodytes $(\mathrm{n}=5), P . t$. verus $(\mathrm{n}=10)$

536 and $P$. paniscus $(\mathrm{n}=9)$, the $100 \%$ classification accuracy of lower second molars based on

537 anatomically-based landmarks on the EDJ was matched with $100 \%$ classification accuracy of 
538 lower second molars based on mathematically-derived measurements on and around the OES.

539 The improvement in classification accuracy compared to the previous comparison of 110

540 specimens is an artefact of sampling: smaller sample sizes and a smaller subset of taxa were used

541 to match those used in Skinner et al. (2009). In particular, the exclusion of P. t. schweinfurthii,

542 which overlaps in molar size and shape with $P$. t. troglodytes improves classification accuracy.

543 Given this identical result in classification, the mathematical landmarking method might

544 therefore provide a means to assess how well the EDJ taxonomic signal relates to that of the

545 OES, as discussed by Skinner et al. (2009), providing a solution to both of the frustrations

546 experienced by this group of researchers - the scarcity of unworn teeth in museum collections

547 and the problem of the need for increased subjectivity in the placement of landmarks on a worn

548 OES, as compared to the well-defined ridges of the EDJ. Since landmarking only takes a few

549 minutes to complete, this might enable quick verifications to be made, confirming the results of

550 the EDJ analyses.

551 The results from the comparative analyses provide a reasonable level of comfort that the

552 mathematically-based methodology of landmarking the crown surface might readily replace

553 more traditional methods based on anatomical landmarks, to enable worn teeth to be included on

554 an equal basis with unworn teeth in morphometric analyses. Worn teeth might include individual

555 specimens of importance (particularly fossil hominin holotypes or paratypes) and important

556 groups (e.g. modern human hunter-gatherer groups, whose teeth tend to be more heavily worn

557 than groups with soft diets). Inclusion of worn teeth allows for the augmentation of poorly-

558 represented fossil hominin species and for the balance between groups to be improved (e.g.

559 between males and females, or between different extant populations). Provided that the outline

560 shape and the five cusp intersections are identifiable on the image, landmarking is possible, 
561 irrespective of the lack of sharpness of features on the surface. Although the present study

562 necessarily made use of relatively unworn teeth, to enable comparison of classification accuracy

563 with previous studies that used unworn teeth, further papers are being prepared where the

564 methodology is applied in classifying worn fossil hominin and modern human molars. The

565 methodology is designed to be adaptable for all extant hominoid and extinct hominin molars, for

566 all types of analysis involving landmarks or measurement variables, and for all levels of group

567 comparison at the level of genus, species, subspecies, population and sex.

568

569

570

571

572

573

574

575

576

577

578

579

580

581

582

583

584

\section{Conclusions}

Enamel crown surfaces of lower second molars provide reliable data for use in extant hominoid systematics studies, and by extension, they are reliably applied to extinct hominin taxonomic studies as well. Diagnostic features of the enamel surface of molar crowns include the general proportions of molars, size, occlusal outline shapes and the dimensions and orientations of cusps, both in relation to each other and to the longitudinal axis of the molar. In this study, the mathematical placement of landmarks not only around the perimeter outline of the molar but also at cusp centers and midlines allows for shape and size analyses, as well as analyses that make use of cusp angles and dimensions. Euclidean coordinates may be used directly in geometric morphometric studies, or distances and angles between landmarks may be calculated for analyses using raw measurements.

This study seeks to establish whether strategically-sited mathematically-derived landmarks on and around the enamel surface of molars produce good discrimination between groups in morphospace (at the species and subspecies levels) and classification accuracy that is at least as high as that derived from using traditional, anatomically-derived measurements and 
585 landmarks. The method was tested on 110 lower second molars representing five hominoid

586 species (eight subspecies). Good separation of groups in morphospace was achieved after a

587 generalized Procrustes analysis in a shapespace (shape-only) principal components analysis. This

588 grouping was further improved by adding size as a variable into the analysis, in a formspace

589 (shape-size) principal components analysis, this time allowing for visualization of sexual

590 dimorphism between male and female gorillas and for separate groupings of bonobo and

591 common chimpanzee molars. Classification accuracy of $96.4 \%$ at the species level and $88.2 \%$ at

592 the subspecies level was achieved in a discriminant function analysis, using only nine linear and

593 angular measurements. Comparing the classification accuracy of these mathematically-derived

594 measurements to the traditional, anatomically-based methodologies used in two existing studies

595 (Pilbrow, 2006 and Skinner et al., 2009), the results are identical (as compared to Skinner et al.,

596 2009) or marginally improved (as compared to the type of methodology described in Pilbrow,

597 2006), providing comfort that the methodology may confidently be used as an alternative to

598 methodologies relying entirely on identifiable anatomical features. Worn molars may be

599 therefore be included equally confidently as unworn or moderately-worn molars in geometric

600 morphometric and other statistical studies, even if the enamel surface is severely damaged, but

601 the perimeter edge of the tooth and the cusp intersections are still clearly identifiable. This is

602 crucial for studies where sample sizes are low, such as in analyses involving fossil hominin

603 molars; indeed, in some cases, the sample, usually already limited, includes holotypes or proxies

604 for holotypes with extremely worn molars. The same advantage holds when an imbalance exists

605 in the availability of relatively unworn teeth between males and females in a sample, between

606 geographical groups, subspecies, or diet-based groupings (where some groups may have heavily

607 worn teeth but others might not). 
609 expertise, and can be carried out using readily available software. We conclude that this

610 methodology provides results that are equally as accurate as methodologies based on anatomical

611 landmark sites, and that it can be recommended for augmentation of sample sizes in studies

612 involving worn teeth.

613

\section{Acknowledgements}

615 The authors are grateful for the comments and suggestions provided by reviewers of this paper.

616 Susan J Dykes extends sincere thanks to the following museums/collections for access to modern

617 human dental material: The Raymond Dart collection at the University of the Witwatersrand,

618 Johannesburg; the Iziko museum, Cape Town; the Musée de l'Homme, Paris; the Duckworth

619 collection at Cambridge University.

620 Varsha C Pilbrow acknowledges the following museums for access to chimpanzee and gorilla

621 dental material: American Museum of Natural History, NY; Anthropologisches Institüt und

622 Museum der Universität Zürich-Irchel, Zürich; British Museum of Natural History, London;

623 Field Museum of Natural History, Chicago; Museum of Comparative Zoology, Harvard;

624 Muséum National d'Histoire Naturelle, Paris; Powell-Cotton Museum, Kent; Peabody Museum

625 of Anthropology, Harvard; United States National Museum, Washington, D.C.; Musée Royal de

626 l'Afrique Centrale, Tervuren; Zoologisches Museum, Berlin; Anthropologische und Zoologische

627 Staassammlung, Münich.

628 


\section{References}

630 Ackermann, R. R. (2003). Using extant morphological variation to understand fossil

631 relationships: A cautionary tale. South African Journal of Science, 99, 255-258.

632 Albrecht, G.H., Miller, J.M.A. (1993). Geographic variation in primates: a review with

633 implications for interpreting fossils. In: Kimbel, W.H. and Martin, L.B. (Eds), Species,

634 Species Concepts, and Primate Evolution. Plenum Press, New York, pp. 123-161.

635 Albrecht, G.H., Gelvin, B.R., Miller, J.M.A., (2003). The hierarchy of intraspecific craniometrics

636 variation in gorillas: a population-thinking approach with implications for fossil species

637 recognition studies. In: Taylor, A.B. and Goldsmith, M.L. (Eds.), Gorilla Biology.

638 Cambridge University Press, Cambridge, pp. 62-103.

639 Baab, K. L. (2008). The taxonomic implications of cranial shape variation in Homo erectus.

640 Journal of Human Evolution, 54(6), 827-847. http://doi.org/10.1016/j.jhevol.2007.11.003

641 Bailey, S. E. (2004). A morphometric analysis of maxillary molar crowns of Middle-Late

642 Pleistocene hominins. Journal of Human Evolution, 47(3), 183-198.

643 http://doi.org/10.1016/j.jhevol.2004.07.001

644 Bailey, S. E., Pilbrow, V. C. and Wood, B. A. (2004). Interobserver error involved in

645 independent attempts to measure cusp base areas of Pan M1s. Journal of Anatomy, 205(4),

646 323-331. http://doi.org/10.1111/j.0021-8782.2004.00334.x

647 Bailit, H. L. and Friedlaender, J. (1966). Tooth size reduction a hominid trend. American

648 Anthropologist, (Weiner 1954), 665-672.

649 Benazzi, S., Coquerelle, M., Fiorenza, L., Bookstein, F., Katina, S., Kullmer, O. (2011).

650 Comparison of dental measurement systems for taxonomic assignment of first molars.

651 American Journal of Physical Anthropology, 144, 342-354. 
652 Benazzi, S., Fornai, C., Buti, L., Toussaint, M., Mallegni, F., Ricci, S., Gruppioni, G., Weber, G.

653 W., Condemi, S. and Ronchitelli, A. (2012). Cervical and crown outline analysis of worn

654 Neanderthal and modern human lower second deciduous molars. American Journal of

655 Physical Anthropology, 149(4), 537-546. http://doi.org/10.1002/ajpa.22155

656 Bergl, R.A. (2006). Conservation Biology of the Cross River Gorilla (Gorilla gorilla diehli).

657 New York. City University of New York.

658 Bookstein, F. L. (1991). Morphometric tools for landmark data: geometry and biology.

659 Cambridge University Press, Cambridge.

660 Bookstein, F. L. (1996/7). Landmark methods for forms without landmarks: morphometrics of

661 group differences in outline shape. Medical Image Analysis (1996/7) volume 1, number 3, $662 \quad 225-243$.

663 Boyde, A. (1997). Microstructure of enamel. In Dental Enamel. Ciba Foundation Symposium

664 Series, vol. 205, eds: H.C. Slavkin, D.J. Chadwick, G. Cardew and G. B. Winter. New $665 \quad$ York, Wiley.

666 Brace, C. L., \& Mahler, P. E. (1971). Post-Pleistocene changes in the human dentition. American 667 Journal of Physical Anthropology, 34(2), 191-203. http://doi.org/10.1002/ajpa.1330340205

668 Brace, C. L., Rosenberg, K. R., \& Hunt, K. D. (1987). Gradual change in human tooth size in the 669 late Pleistocene and post-Pleistocene. Evolution, 41(4), 705-720.

670 Braga, J.C., 1995. Définition de certains caractères discrets crâniens chez Pongo, Gorilla, et Pan.

671 Perspectives taxonomiques et phylogénétiques. Ph.D. Dissertation, Univeristy of Bordeaux.

672 Braga, J., Thackeray, J. F., Subsol, G., Kahn, J. L., Maret, D., Treil, J., \& Beck, A. (2010). The 673 enamel-dentine junction in the postcanine dentition of Australopithecus africanus: intra- 
674

675

676

677

678

679

680

681

682

683

684

685

686

687

688

689

690

691

692

693

694

individual metameric and antimeric variation. Journal of Anatomy, 216(1), 62-79. http://doi.org/10.1111/j.1469-7580.2009.01154.x

Braun, S., Thackeray, J. F., \& Loots, M. (2004). Scientific notes: A morphometric technique to assess probabilities of conspecificity in extant primates and Plio-Pleistocene hominids. Annals of the Transvaal Museum, 41, 93-95.

Brown, P., \& Maeda, T. (2004). Post-Pleistocene diachronic change in East Asian facial skeletons: the size, shape and volume of the orbits. Anthropological Science, 112, 29-40. http://doi.org/10.1537/ase.00072

Butynski, T. (2003). The robust chimpanzee Pan troglodytes: taxonomy, distribution, abundance, and conservation status. In West African Chimpanzees. Status Survey and Conservation Action Plan pp. 5-12

Corruccini, R. S. (1984). An epidemiologic transition in dental occlusion in world populations. American Journal of Orthodontics, 86(5), 419-426. http://doi.org/10.1016/S00029416(84)90035-6

Corruccini, R. S., Potter, R. H. Y., \& Dahlberg, A. A. (1983). Changing occlusal variation in Pima Amerinds. American Journal of Physical Anthropology, 62(3), 317-324. http://doi.org/10.1002/ajpa.1330620311

Crevecoeur, I., Skinner, M. M., Bailey, S. E., Gunz, P., Bortoluzzi, S., Brooks, A. S., Burlet, C., Cornelissen, E., De Klerck, N., Maureille, B., Semal, P., Vanbrabant, Y. and Wood, B. (2014). First early hominin from Central Africa (Ishango, Democratic Republic of Congo). PLoS ONE, 9(1), e84652. http://doi.org/10.1371/journal.pone.0084652 
695 Dempsey, P. J., \& Townsend, G. C. (2001). Genetic and environmental contributions to variation

696 in human tooth size. Heredity, 86(6), 685-693. http://doi.org/10.1046/j.1365-

$697 \quad 2540.2001 .00878 . x$

698 Dykes, S. J. (2014). A morphometric analysis of hominin teeth attributed to Australopithecus,

699 Paranthropus and Homo. MSc. Dissertation, University of the Witwatersrand,

$700 \quad$ Johannesburg, South Africa.

701 Dykes, S. J. (2018). Shape and size variability in lower second molars of extant hominoids and

702 extinct hominin species with particular reference to modern Homo sapiens and its potential

703 for the use as an analogue species in the context of fossil hominin dental variability

704 comparisons. PhD Thesis, University of the Witwatersrand, Johannesburg, South Africa.

705 Emes, Y., Aybar, B., \& Yalcin, S. (2011). On the evolution of human jaws and teeth: a review.

706 Bulletin of the International Association of Paleodontology, 5(1), 37-47.

707 Ferguson, W. W. (1989). Critique of "Australopithecus afarensis" as a single species based on

708 dental metrics and morphology. Primates. 30(4), 561-569.

709 http://doi.org/10.1007/BF02380881

710 Gómez-Robles, A., Martinón-Torres, M., Bermúdez de Castro, J. M., Margvelashvili, A., Bastir,

711 M., Arsuaga, J. L., Pérez-Pérez, A., Estebaranz, F. and Martínez, L. M. (2007). A

712 geometric morphometric analysis of hominin upper first molar shape. Journal of Human

713 Evolution, 53(3), 272-285. http://doi.org/10.1016/j.jhevol.2007.02.002

714 Gómez-Robles, A., Martinón-Torres, M., Bermúdez de Castro, J. M., Prado-Simón, L.,

715 Sarmiento, S., and Arsuaga, J. L. (2008). Geometric morphometric analysis of the crown

716 morphology of the lower first premolar of hominins, with special attention to Pleistocene

717 Homo. Journal of Human Evolution, 55, 627-638. 
718 Gómez-Robles, A., Bermúdez de Castro, J. M., Martinón-Torres, M., Prado-Simón, L., Arsuaga,

719 J. L., Gómez-Robles, A. and Arsuaga, J. L. (2012). A geometric morphometric analysis of

720 hominin upper second and third molars, with particular emphasis on European Pleistocene

721 populations. Journal of Human Evolution, 63(3), 512-526.

722 http://doi.org/10.1016/j.jhevol.2012.06.002

723 Gómez-Robles, A., Bermúdez de Castro, J. M., Martinón-Torres, M., Prado-Simón, L., and

724 Arsuaga, J. L. (2015). A geometric morphometric analysis of hominin lower molars:

725 Evolutionary implications and overview of postcanine dental variation. Journal of Human

726 Evolution, 82, 34-50. http://doi.org/10.1016/j.jhevol.2015.02.013

727 Gonder, M. K., Locatelli, S., Ghobrial, L., Mitchell, M. W., Kujawski, J. T., Lankester, F. J.,

728 Stewart, C.-B. and Tishkoff, S. A. (2011). Evidence from Cameroon reveals differences in

729 the genetic structure and histories of chimpanzee populations. Proceedings of the National

730 Academy of Sciences of the United States of America, 108(12), 4766-71.

$731 \quad$ http://doi.org/10.1073/pnas. 1015422108

732 Goose, D. H. (1963) Dental Anthropology. London: Pergamon Press

733 Grine, F. E. (2002). Scaling of tooth enamel thickness, and molar crown size reduction in

734 modern humans. South African Journal of Science, 98(9-10), 503-509.

735 Grine, F. E. (2005). Enamel thickness of deciduous and permanent molars in modern Homo

736 sapiens. American Journal of Physical Anthropology, 126(1), 14-31.

737 Hey, J. (2010). The divergence of chimpanzee species and subspecies as revealed in

738 multipopulation isolation-with-migration analyses. Molecular Biology and Ecolution, 27(4),

$739921-933$. 
740 Hodder, I. (2017). Things and the Slow Neolithic: the Middle Eastern Transformation. Journal of

741 Archaeological Method and Theory, pp. 1-23. http://doi.org/10.1007/s10816-017-9336-0

742 Jungers, W. L., Susman, R. L. (1984). Body size and skeletal allometry in African apes. In:

743 Susman, R. L. (eds) The Pygmy Chimpanzee. Springer. Boston, MA.

744 Junker, J., Blake, S., Boesch, C., Campbell, G., du Toit, L., Duvall, C., Ekobo, A., Etoga, G.,

745 Galat-Luong, A., Gamys, J., Ganas-Swaray, J., Gatti, S., Ghiurghi, A., Granier, N., Hart, J.,

746 Head, J., Herbinger, I., Cleveland Hicks, T., Huijbregts, B., Imong, I. S., Kuempel, N.,

747 Lahm, S., Lindsell, J., Maisels, F., McLennan, M., Martinez, L., Morgan, B., Morgan, D.,

748 Mulindahabi, F., Mundry, R., N'Goran, K. P., Normand, E., Ntongho, A., Okon, D. T.,

749 Petre, C.-A., Plumptre, A., Rainey, H., Regnaut, S., Sanz, C., Stokes, E., Tondossama, A.,

750 Tranquilli, S., Sunderland-Groves, S., Walsh, P., Warren, Y., Williamson, E. A. and Kuehl,

751 H. S. (2012). Recent decline in suitable environmental conditions for African great

752 apes. Divers. Distrib. 18, 1077-1091.

753 Kalpers, J., Williamson, E.A., Robbins, M.M., McNeilage, A., Nzamurambaho, A., Lola, N. and

754 Mugiri, G. (2003). Gorillas in the crossfire: population dynamics of the Virunga mountain

755 gorillas over the past three decades. Oryx 37(3), 326-337.

756 Kimbel, W. H., \& Martin, L. (Eds.). (1993). Species, species concepts, and primate evolution.

$757 \quad$ New York: Plenum Press.

758 Kormos, R., Boesch, C., Bakarr, M. I., \& Butynski, T. M. (2003). Status Survey and

759 Conservation Action Plan: West African Chimpanzees. IUCN, Gland, Switzerland.

760 Larsen, C. S. (1995). Biological Changes in Human Populations with Agriculture. Annual

$761 \quad$ Review of Anthropology, 24, 185-213. 
762 Lee, S.-H. (2005). Patterns of size sexual dimorphism in Australopithecus afarensis: another

763 look. Homo : Internationale Zeitschrift Fur Die Vergleichende Forschung Am Menschen,

764 56(3), 219-232. http://doi.org/10.1016/j.jchb.2005.07.001

765 Lordkipanidze, D., Ponce de León, M. S., Margvelashvili, A., Rak, Y., Rightmire, G. P. P.,

766 Vekua, A., and Zolikofer, C. P. (2013). A complete skull from Dmanisi, Georgia, and the

767 evolutionary biology of Early Homo. Science (New York, N.Y.), 342(6156), 326-31.

$768 \quad$ http://doi.org/10.1126/science. 1238484

769 Manly, B. F. J (2005) Multivariate statistical methods. Chapman \& Hall/CRC, Boca Raton, FL.

770 Martinón-Torres, M., Bastir, M., Bermúdez de Castro, J. M., Gómez-Robles, A., Sarmiento, S.,

771 Muela, A., and Arsuaga, J. L. (2006). Hominin lower second premolar morphology:

772 evolutionary inferences through geometric morphometric analysis. Journal of Human

773 Evolution, 50(5), 523-533. http://doi.org/10.1016/j.jhevol.2005.12.004

774 Mitteroecker, P., Gunz, P., Bernhard, M., Schaefer, K., \& Bookstein, F. L. (2004). Comparison

775 of cranial ontogenetic trajectories among great apes and humans. Journal of Human

776 Evolution, 46(6), 679-698. http://doi.org/10.1016/j.jhevol.2004.03.006

777 Mitteroecker, P., Gunz, P., Windhager, S., \& Schaefer, K. (2013). A brief review of shape, form,

778 and allometry in geometric morphometrics, with applications to human facial morphology.

779 Hystrix, 24(1), 59-66. http://doi.org/10.4404/hystrix-24.1-6369

780 Nater, A., Mattle-greminger, M. P., Nurcahyo, A., Marques-bonet, T., \& Meijaard, E. (2017).

781 Morphometric, Behavioral, and Genomic Evidence for a New Orangutan Species. Current

782 Biology, 27, 1-12. http://doi.org/10.1016/j.cub.2017.09.047

783 Oates JF (1996) African Primates: Status Survey and Conservation Plan. Gland Press,

$784 \quad$ Cambridge. 
785 Oates JF, Sunderland-Groves J, Bergl R, Dunn A, Nicholas A, Takang E, Omeni F, Imong I,

786 Fotso R, Nkembi L \& Williamson EA (2007) Regional Action Plan for the Conservation of

787 the Cross River Gorilla (Gorilla gorilla diehli). Oates J F, Sunderland-Groves Jacqueline,

788 Bergl Richard, Dunn Andrew, Nicholas Aaron, Takang Ebai, Omeni Fidelis, Imong

789 Inaoyom, Fotso Roger, Nkembi Louis, Williamson Liz (ed.). IUCN/SSC Primate Specialist

$790 \quad$ Group and Conservation International.

791 Pilbrow, V.C., (2003). Dental variation in African apes with implications for understanding

792 patterns of variation in species of fossil apes. Ph.D. Dissertation, New York University.

793 Pilbrow, V.C., (2006). Population systematics of chimpanzees using molar morphometrics. J.

794 Hum. Evol. 51(6), 646-662.

795 Pilbrow, V. (2007). Patterns of molar variation in great apes and their implications for hominin 796 taxonomy. Dental Perspectives on Human Evolution: State of the Art Research in Dental

797 Paleoanthropology, 9-32. Retrieved from http://dx.doi.org/10.1007/978-1-4020-5845-5_2

798 Pilbrow, V. (2010). Dental and phylogeographic patterns of variation in gorillas. Journal of

799 Human Evolution, 59(1), 16-34. http://doi.org/10.1016/j.jhevol.2010.01.009

800 Pinhasi, R., Eshed, V., \& Shaw, P. (2008). Evolutionary changes in the masticatory complex

801 following the transition to farming in the southern Levant. American Journal of Physical

$802 \quad$ Anthropology2, 135(2), 136-148.

803 Plavcan, J. M., \& Cope, D. A. (2001). Metric variation and species recognition in the fossil

804 record. Evolutionary Anthropology, 10(6), 204-222. http://doi.org/10.1002/evan.20001

805 Plumptre, A.J., Rose, R., Nangendo, G., Williamson, E. A., Didier, K., Hart, J., Mulindahabi, F.,

806 Hicks, C., Griffin, B., Ogawa, H., Nixon, S., Pintea, L., Vosper, A., McLennan, M., Amsini,

807 F., McNeilage, A., Makana, J. R., Kanamori, M., Hernandez, A., Piel, A., Stewart, F., 
808

809

810

811

812

813

814

815

816

817

818

819

820

821

822

823

824

825

826

827

828

829

Moore, J., Zamma, K., Nakamura, M., Kamenya, S., Idani, G., Sakamaki, T., Yoshikawa, M., Greer, D., Tranquilli, S., Beyers, R., Hashimoto, C., Furuichi, T., and Bennett, E., (2010). Eastern Chimpanzee (Pan troglodytes schweinfurthii): Status Survey and Conservation Action Plan 2010-2020. IUCN/SSC Primate Specialist Group, Gland, Switzerland.

Richmond, B. G., \& Jungers, W. L. (1995). Size Variation and Sexual Dimorphism in Australopithecus afarensis and Living Hominoids. Journal of Human Evolution, 29(3), 229-245. http://doi.org/10.1006/jhev.1995.1058

Scott, J. E., \& Lockwood, C. A. (2004). Patterns of tooth crown size and shape variation in great apes and humans and species recognition in the hominid fossil record. American Journal of Physical Anthropology, 125(4), 303-319. http://doi.org/10.1002/ajpa.10406

Shea, B.T., Leigh, S. R., Groves, C. P. (1993). Multivariate craniometrics variation in chimpanzees: implications for species identification in paleoanthropology. In: Kimbel, W. H., \& Martin, L. (Eds.). (1993). Species, species concepts, and primate evolution. New York: Plenum Press.

Singleton, M., Rosenberger, A. L., Robinson, C., O’Neill, R. (2011). Allometric and Metameric Shape Variation in Pan Mandibular Molars: A Digital Morphometric Analysis. Anatomical Record, 294(2), 322-334. http://doi.org/10.1002/ar.21315

Skinner, M. M., Gunz, P., Wood, B. A., and Hublin, J.-J. (2008). Enamel-dentine junction (EDJ) morphology distinguishes the lower molars of Australopithecus africanus and Paranthropus robustus. Journal of Human Evolution, 55(6), 979-988.

http://doi.org/10.1016/j.jhevol.2008.08.013 
830 Skinner, M. M., Gunz, P., Wood, B. A., Boesch, C., \& Hublin, J. J. (2009). Discrimination of

831 extant Pan species and subspecies using the enamel-dentine junction morphology of lower

832 molars. American Journal of Physical Anthropology, 140(2), 234-243.

833 http://doi.org/10.1002/ajpa.21057

834 Smith, B. H. (1984). Patterns of molar wear in hunter-gatherers and agriculturalists. American 835 Journal of Physical Anthropology, 63, 39-56.

836 Sofaer, J. A. (1973). A Model Relating Developmental Interaction and Differential Evolutionary 837 Reduction of Tooth Size. Evolution, 27(3), 427-434.

838 Stojanowski, C. M., Johnson, K. M. (2015). Observer error, dental wear, and the inference of 839 New World Sunadonty. American Journal of Physical Anthropology, 156, 349-362.

840 Suwa, G., Wood, B. A., \& White, T. D. (1994). Further analysis of mandibular molar crown and 841 cusp areas in Pliocene and early Pleistocene hominids. American Journal of Physical $842 \quad$ Anthropology, 93, 407-426.

843 Suwa, G., White, T. D., \& Clark Howell, F. (1996). Mandibular postcanine dentition from the 844 Shungura formation, Ethiopia: Crown morphology, taxonomic allocations, and plio845 pleistocene hominid evolution. American Journal of Physical Anthropology, 101(2), 247846 282. http://doi.org/10.1002/(SICI)1096-8644(199610)101:2<247::AID-AJPA9>3.0.CO;2-Z

847 Suwa, G. (1996). Serial allocations of isolated mandibular molars of unknown taxonomic 848 affinities from the Shungura and Unso formations, Ethiopia, a combined method approach. 849 Human Evolution, 11(3-4), 269-282. http://doi.org/10.1007/BF02436630

850 Taylor A. Goldsmith M (eds) (2003) Gorilla Biology: A Multidisciplinary Perspective, pp. 472851 497. Cambridge University Press, Cambridge. 
852 Uchida A (1992) Intra-species variation among the great apes: implications for taxonomy of

853 fossil hominoids. Ph.D. Dissertation, Harvard University.

854 Uchida A (1996) Craniodental Variation among the Great Apes. Peabody Museum of

855 Archeology and Ethnology, Harvard University, Cambridge.

856 Uchida A (1998a). Variation in tooth morphology of Gorilla gorilla. J. Hum. Evol., 34(1), 55-70.

857 Uchida, A. (1998b). Variation in tooth morphology of Pongo pygmaeus. Journal of Human

$858 \quad$ Evolution, 34, 71-79. http://doi.org/10.1006/jhev.1997.0186

859 Uchida, A. (2004) Craniodental variation among the Great Apes. Harvard University Press.

$860 \quad$ Peabody Museum, Bulletin 4:1-184

861 Ungar P. S. (2017). Evolution's Bite: A Story of Teeth, Diet, and Human Origins. New Jersey:

$862 \quad$ Princeton University Press.

863 Vitzthum, V.J. (1984) The implications of interpopulation variation for defining paleospecies.

864 Am. J. Phys. Anthrolol. 63 (Suppl.), 232.

865 Williamson E.A., Fawcett K.A. (2008) Long-term research and conservation of the Virunga

866 mountain gorillas. In: R. Wrangham and E. Ross (eds), Science and Conservation in African

867 Forests: The Benefits of Long-term Research, pp. 213-229. Cambridge University Press,

868 Cambridge, UK.

869 Wolfheim JH (1983) Primates of the World: Distribution, Abundance and Conservation.

$870 \quad$ University of Washington Press, Cambridge, Massachusetts.

871 Wood, B. A. A., \& Abbott, S. A. A. (1983). Analysis of the dental morphology of Plio-

872 pleistocene hominids. I. Mandibular molars: crown area measurements and morphological

873 traits. Journal of Anatomy, 136(Pt 1), 197-219. 
874 Wood, B. A., Abbott, S. A., \& Graham, S. H. (1983). Analysis of the dental morphology of Plio875 Pleistocene hominids. II. Mandibular molars - study of cusp areas, fissure pattern and cross 876 sectional shape of the crown. Journal of Anatomy, $137(\mathrm{Pt} 2)(2), 287-314$.

877 Wood, B. (1991). Koobi Fora Research Project, Volume 4, Hominid Cranial Remains. Clarendon $878 \quad$ Press, Oxford.

879 Wood, B. A., Li, Y., \& Willoughby, C. (1991). Intraspecific variation and sexual dimorphism in 880 cranial and dental variables among higher primates and their bearing on the hominid fossil 881 record. Journal of Anatomy, 174, 185-205.

882

883 


\section{Table 1 (on next page)}

Summary of images of 110 LM2s used in the study 
1 TABLE 1. Summary of images of 110 LM2s used in the study

\begin{tabular}{|c|c|c|c|}
\hline $\begin{array}{l}\text { Species/ } \\
\text { subspecies }\end{array}$ & Population name/geographical areab & Number / Sex & Collections used $^{\mathrm{a}}$ \\
\hline $\begin{array}{l}\text { G. b. beringei } \\
\text { (Eastern } \\
\text { mountain } \\
\text { gorillas) }\end{array}$ & Virunga; Kayonza & $\mathrm{F}=5 ; \mathrm{M}=5$ & $\begin{array}{l}\text { RG; USNM; } \\
\text { BMNH }\end{array}$ \\
\hline $\begin{array}{l}\text { G. b. graueri } \\
\text { (Eastern lowland } \\
\text { gorillas) }\end{array}$ & Utu; Mweng-Fizi; Tshiaberimu & $\mathrm{F}=5 ; \mathrm{M}=5$ & RG \\
\hline $\begin{array}{l}\text { G. g. gorilla } \\
\text { (Western } \\
\text { lowland gorillas) }\end{array}$ & $\begin{array}{l}\text { Coastal Cameroon; Coastal Gabon; } \\
\text { Southern Gabon, Congo; Sangha } \\
\text { River; Upper reaches of Sangha } \\
\text { and Sanaga Rivers; Inland } \\
\text { Cameroon }\end{array}$ & $\begin{array}{c}\mathrm{F}=10 ; \mathrm{M}= \\
10\end{array}$ & $\begin{array}{l}\text { ZMB; BMNH; Z; } \\
\text { PCM; USNM; } \\
\text { RG; MCZ }\end{array}$ \\
\hline $\begin{array}{l}\text { P.t. verus } \\
\text { (Western } \\
\text { chimpanzees) }\end{array}$ & $\begin{array}{l}\text { Between Gambia and Cavally; } \\
\text { between Cavally and Volta }\end{array}$ & $\mathrm{F}=5 ; \mathrm{M}=5$ & $\begin{array}{l}\text { RG; USNM; PM; } \\
\text { AMNH }\end{array}$ \\
\hline $\begin{array}{l}\text { P.t. troglodytes } \\
\text { (Central } \\
\text { chimpanzees) }\end{array}$ & $\begin{array}{l}\text { South Sanaga River; Sanaga River, } \\
\text { inland of coast; Southern Gabon }\end{array}$ & $\mathrm{F}=5 ; \mathrm{M}=5$ & $\begin{array}{l}\mathrm{Z} ; \mathrm{PCM} ; \mathrm{MCZ} \\
\text { RG; ZMB }\end{array}$ \\
\hline $\begin{array}{l}\text { P.t. } \\
\text { schweinfurthii } \\
\text { (Eastern } \\
\text { chimpanzees) }\end{array}$ & $\begin{array}{l}\text { Between Ubangi and Congo-Lisala; } \\
\text { Uele River; Kisangani district; } \\
\text { Lake Albert to north of Lake } \\
\text { Tanganyika; Lake Kivu and Lake } \\
\text { Tanganyika }\end{array}$ & $\mathrm{F}=5 ; \mathrm{M}=5$ & $\begin{array}{l}\mathrm{RG} ; \mathrm{MBNH} \\
\quad \mathrm{ZMB}\end{array}$ \\
\hline $\begin{array}{l}\text { P. paniscus } \\
\text { (Bonobos) }\end{array}$ & $\begin{array}{l}\text { Between Congo and Lukenie; } \\
\text { between Lomami and Congo; } \\
\text { between Lukeni and Kasai }\end{array}$ & $\begin{array}{c}\mathrm{F}=10 ; \mathrm{M}= \\
10\end{array}$ & $\mathrm{RG} ; \mathrm{MCZ}$ \\
\hline $\begin{array}{l}\text { H. sapiens } \\
\text { (Recent modern } \\
\text { humans) }\end{array}$ & $\begin{array}{l}\text { Southern African KhoeSan (hunter- } \\
\text { gatherer); Kenya - Babinga (hunter- } \\
\text { gatherer); Kenya - Teita } \\
\text { (subsistence farming); Australian } \\
\text { Aboriginal (hunter-gatherer); } \\
\text { Melanesia (horticulturalists); South } \\
\text { Asia (predominantly } \\
\text { agriculturalists); Balkan region } \\
\text { (predominantly agriculturalists); } \\
\text { Near East (predominantly }\end{array}$ & $\begin{array}{c}\mathrm{F}=10 ; \mathrm{M}= \\
10\end{array}$ & $\begin{array}{l}\text { Iziko; Dartc; } \\
\text { MNHN; CAM- } \\
\text { DL }\end{array}$ \\
\hline
\end{tabular}


agriculturalists); Western Europe

(predominantly agriculturalists)

$2{ }^{a}$ Museum/collections are as follows: AMNH - American Museum of Natural History, New

3 York; BMNH - British Museum of Natural History, London; CAM-DL - Duckworth Collection,

4 Cambridge University; Dart - Raymond Dart Collection, Anatomical Sciences, University of the

5 Witwatersrand, Johannesburg; Iziko - Iziko Museum, Cape Town; MNHN - Muséum National

6 d'Histoire Naturelle, Paris (Musée de l'Homme) ; PCM - Powell-Cotton Museum, Kent ; RG -

7 Musée Royal de L'Afrique Centrale, Tervuren, Belgium; USNM - United States National

8 Museum, Washington, D.C.; Z - Anthropologisches Institüt und Museum der Universität Zürich-

9 Irchel, Zürich; ZMB - Zoologisches Museum, Berlin

10 b Pilbrow (2006); Pilbrow (2010)

$11{ }^{\mathrm{c}}$ University of the Witwatersrand, Johannesburg, Blanket Ethics Waiver Number W-CJ-14064-1 
Table 2 (on next page)

Description of landmark sites 
1 TABLE 2. Description of landmark sites

\# Type Description

1 III Mathematical center of bounding box

2 III Mesial-most extent of the molar, placed midway down the mesial side of the bounding box

3 III Lingual-most extent of the molar, placed midway across the lingual side of the bounding box

4 III Distal-most extent of the molar, placed midway down the distal side of the bounding box

5 III Buccal-most extent of the molar, placed midway across the buccal side of the bounding box

6 I Anatomical landmark at the groove between the metaconid and protoconid on the perimeter of the crown (corrected for interstitial wear).

7 I Anatomical landmark at the groove between the metaconid and entoconid on the perimeter of the crown.

8 I Anatomical landmark at the groove between the protoconid and hypoconulid on the perimeter of the crown.

9 I Anatomical landmark at the groove between the hypoconulid and hypoconid on the perimeter of the crown.

10 I Anatomical landmark at the groove between the hypoconid and protoconid on the perimeter of the crown.

11 III Midpoint of the line between landmarks 6 and 7.

12 III Midpoint of the line between landmarks 7 and 8.

13 III Midpoint of the line between landmarks 8 and 9.

14 III Midpoint of the line between landmarks 9 and 10.

15 III Midpoint of the line between landmarks 10 and 6.

16 III Midpoint of the arc/curve at the perimeter of the metaconid created by extending a straight line from landmark 1 through landmark 11 to the perimeter. 
17 III Midpoint of the arc at the perimeter of the entoconid created by extending a straight line from landmark 1 through landmark 12 to the perimeter.

18 III Midpoint of the arc at the perimeter of the hypoconulid created by extending a straight line from landmark 1 through landmark 13 to the perimeter.

19 III Midpoint of the arc at the perimeter of the hypoconid created by extending a straight line from landmark 1 through landmark 14 to the perimeter.

20 III Midpoint of the arc at the perimeter of the protoconid created by extending a straight line from landmark 1 through landmark 15 to the perimeter.

21 III Mathematically-derived proxy for the center point of the metaconid, placed at the midpoint of the line from landmark 1 to landmark 16

22 III Mathematically-derived proxy for the center point of the entoconid, placed at the midpoint of the line from landmark 1 to landmark 17

23 III Mathematically-derived proxy for the center point of the hypoconulid, placed at the midpoint of the line from landmark 1 to landmark 18

24 III Mathematically-derived proxy for the center point of the hypoconid, placed at the midpoint of the line from landmark 1 to landmark 19

25 III Mathematically-derived proxy for the center point of the protoconid, placed at the midpoint of the line from landmark 1 to landmark 20

26 III Point on the lingual edge of metaconid placed by extending a line from the center point of metaconid to the lingual edge of the tooth.

27 III Point on the lingual edge of entoconid placed by extending a straight line from the center point of entoconid to the lingual edge of the tooth.

28 III Point on the buccal edge of hypoconid placed by extending a straight line from the center point of hypoconid to the buccal edge of the tooth.

29 III Point on the buccal edge of protoconid placed by extending a straight line from the center point of protoconid to the buccal edge of the crown. 


\section{Table 3 (on next page)}

List of mathematically-derived measurements used for input into discriminant function analyses in this study 
1 TABLE 3. List of mathematically-derived measurements used for input into discriminant

2 function analyses in this study

\# Measurement

1 Mesiodistal (MD) diameter

2 Buccolingual breadth across mesial cusps

3 Buccolingual breadth across distal cusps

$4 \quad$ Breadth across buccolingual groove

$5 \quad$ Length of mesial edge of buccal development groove

$6 \quad$ Length of distal edge of buccal development groove

$7 \quad$ Angle of mesial cusps

$8 \quad$ Angle of distal cusps

9 Hypoconulid curvature ratio
Description

Between landmarks 2 and 4

Between landmarks 26 and 29

Between landmarks 27 and 28

Between landmarks 7 and 10

Between landmarks 29 and 10

Between landmarks 10 and 28

Angle between line connecting centers of mesial cusps (landmarks 21 and 25) and the MD diameter (line between landmarks 2 and 4)

Angle between line connecting centers of distal cusps (landmarks 22 and 24) and the MD diameter (line between landmarks 2 and 4)

The extent of the outward projection of the of the arc of the hypoconulid at the perimeter, in relation to the total length between the tooth center and the midpoint of the hypoconulid at the perimeter, to measure flatness or curvature of the hypoconulid (landmarks $13-18$, divided by landmarks $1-18$ ) 


\section{Table 4 (on next page)}

Classification accuracy of 110 LM2s at species level using mathematically-derived measurements 
1 TABLE 4. Classification accuracy of 110 LM2s at species level using mathematically-derived 2 measurements

\begin{tabular}{llllllll}
\hline & Species & $\begin{array}{l}\text { G. } \\
\text { beringei }\end{array}$ & $\begin{array}{l}\text { G. } \\
\text { gorilla }\end{array}$ & P. troglodytes & $\begin{array}{l}\text { P. } \\
\text { paniscus }\end{array}$ & $\begin{array}{l}H . \\
\text { sapiens }\end{array}$ & $\mathrm{N}$ \\
\hline Original & G. beringei & 18 & 2 & 0 & 0 & 0 & 20 \\
& G. gorilla & 1 & 19 & 0 & 0 & 0 & 20 \\
& P. troglodytes & 0 & 0 & 29 & 1 & 0 & 30 \\
& P. paniscus & 0 & 0 & 0 & 20 & 0 & 20 \\
& H. sapiens & 0 & 0 & 0 & 0 & 20 & 20 \\
\hline Cross- & G. beringei & 17 & 3 & 0 & 0 & 0 & 20 \\
& G. gorilla & 2 & 18 & 0 & 0 & 0 & 20 \\
& P. troglodytes & 0 & 0 & 29 & 1 & 0 & 30 \\
& P. paniscus & 0 & 0 & 1 & 19 & 0 & 20 \\
& H. sapiens & 0 & 0 & 0 & 1 & 19 & 20 \\
\hline
\end{tabular}

$96.4 \%$ of original grouped cases correctly classified.

$92.7 \%$ of cross-validated grouped cases correctly classified.

3 


\section{Table 5 (on next page)}

Classification accuracy of $110 \mathrm{LM} 2 \mathrm{~s}$ at subspecies level using mathematically-derived measurements 
1 TABLE 5. Classification accuracy of 110 LM2s at subspecies level using mathematically2 derived measurements

\begin{tabular}{|c|c|c|c|c|c|c|c|c|c|c|}
\hline & Subspecies & $\begin{array}{l}\text { G. } b . \\
\text { beringei }\end{array}$ & $\begin{array}{l}\text { G. b. } \\
\text { graueri }\end{array}$ & $\begin{array}{l}\text { G. g. } \\
\text { gorilla }\end{array}$ & $\begin{array}{l}\text { P.t. } \\
\text { verus }\end{array}$ & $\begin{array}{l}\text { P.t. } \\
\text { troglodytes }\end{array}$ & $\begin{array}{l}\text { P.t. } \\
\text { schweinfurthii }\end{array}$ & $\begin{array}{l}P . \\
\text { paniscus }\end{array}$ & $\begin{array}{l}H . \\
\text { sapiens }\end{array}$ & $\mathrm{N}$ \\
\hline \multirow[t]{8}{*}{ Original } & G. b. beringei & 8 & 1 & 1 & 0 & 0 & 0 & 0 & 0 & 10 \\
\hline & G. b. graueri & 2 & 7 & 1 & 0 & 0 & 0 & 0 & 0 & 10 \\
\hline & G. g. gorilla & 1 & 1 & 18 & 0 & 0 & 0 & 0 & 0 & 20 \\
\hline & P.t. verus & 0 & 0 & 0 & 9 & 1 & 0 & 0 & 0 & 10 \\
\hline & $\begin{array}{l}\text { P.t. } \\
\text { troglodytes }\end{array}$ & 0 & 0 & 0 & 0 & 8 & 1 & 1 & 0 & 10 \\
\hline & $\begin{array}{l}\text { P.t. } \\
\text { schweinfurthii }\end{array}$ & 0 & 0 & 0 & 0 & 2 & 8 & 0 & 0 & 10 \\
\hline & P. paniscus & 0 & 0 & 0 & 0 & 1 & 0 & 19 & 0 & 20 \\
\hline & H. sapiens & 0 & 0 & 0 & 0 & 0 & 0 & 0 & 20 & 20 \\
\hline \multirow{8}{*}{$\begin{array}{l}\text { Cross- } \\
\text { validated }\end{array}$} & G. b. beringei & 6 & 3 & 1 & 0 & 0 & 0 & 0 & 0 & 10 \\
\hline & G. b. graueri & 3 & 6 & 1 & 0 & 0 & 0 & 0 & 0 & 10 \\
\hline & G. g. gorilla & 1 & 1 & 18 & 0 & 0 & 0 & 0 & 0 & 20 \\
\hline & P. t. verus & 0 & 0 & 0 & 9 & 1 & 0 & 0 & 0 & 10 \\
\hline & $\begin{array}{l}\text { P.t. } \\
\text { troglodytes }\end{array}$ & 0 & 0 & 0 & 0 & 7 & 2 & 1 & 0 & 10 \\
\hline & $\begin{array}{l}\text { P.t. } \\
\text { schweinfurthii }\end{array}$ & 0 & 0 & 0 & 1 & 4 & 5 & 0 & 0 & 10 \\
\hline & P. paniscus & 0 & 0 & 0 & 0 & 1 & 0 & 19 & 0 & 20 \\
\hline & H. sapiens & 0 & 0 & 0 & 2 & 1 & 0 & 0 & 17 & 20 \\
\hline
\end{tabular}

$88.2 \%$ of original grouped cases correctly classified.

$79.1 \%$ of cross-validated grouped cases correctly classified.

3 
Table 6(on next page)

Classification accuracy of 110 LM2s at species level using anatomically-derived measurements 
1 TABLE 6. Classification accuracy of 110 LM2s at species level using anatomically-derived 2 measurements

\begin{tabular}{llllllll}
\hline & Species & $G$. & $G$. & $P$. & $\begin{array}{l}P . \\
\text { paniscus }\end{array}$ & $\begin{array}{l}\text { H. } \\
\text { sapiens }\end{array}$ & $\mathrm{N}$ \\
\hline Original & G. beringei & 17 & 3 & 0 & 0 & 0 & 20 \\
& G. gorilla & 3 & 17 & 0 & 0 & 0 & 20 \\
& P. troglodytes & 0 & 0 & 30 & 0 & 0 & 30 \\
& P. paniscus & 0 & 0 & 0 & 19 & 1 & 20 \\
& H. sapiens & 0 & 0 & 0 & 1 & 19 & 20 \\
\hline Cross- & G. beringei & 15 & 5 & 0 & 0 & 0 & 20 \\
& G. gorilla & 3 & 17 & 0 & 0 & 0 & 20 \\
& P. troglodytes & 0 & 0 & 0 & 30 & 0 & 30 \\
& P. paniscus & 0 & 0 & 0 & 19 & 1 & 20 \\
& H. sapiens & 0 & 0 & 0 & 1 & 19 & 20
\end{tabular}

$93.6 \%$ of original grouped cases correctly classified.

$90.9 \%$ of cross-validated grouped cases correctly classified.

3

4 


\section{Table 7 (on next page)}

Classification accuracy of 110 LM2s at subspecies level using anatomically-derived measurements 
1 TABLE 7. Classification accuracy of 110 LM2s at subspecies level using anatomically-derived 2 measurements

\begin{tabular}{|c|c|c|c|c|c|c|c|c|c|c|}
\hline & Subspecies & $\begin{array}{l}\text { G. } b \text {. } \\
\text { beringei }\end{array}$ & $\begin{array}{l}\text { G. } b . \\
\text { graueri }\end{array}$ & $\begin{array}{l}\text { G. g. } \\
\text { gorilla }\end{array}$ & $\begin{array}{l}\text { P.t. } \\
\text { verus }\end{array}$ & $\begin{array}{l}\text { P. } t . \\
\text { troglodytes }\end{array}$ & $\begin{array}{l}\text { P. } t . \\
\text { schweinfurthii }\end{array}$ & $\begin{array}{l}P . \\
\text { paniscus }\end{array}$ & $\begin{array}{l}H . \\
\text { sapiens }\end{array}$ & $\mathrm{N}$ \\
\hline \multirow[t]{8}{*}{ Original } & G. b. beringei & 5 & 3 & 2 & 0 & 0 & 0 & 0 & 0 & 10 \\
\hline & G. b. graueri & 2 & 7 & 1 & 0 & 0 & 0 & 0 & 0 & 10 \\
\hline & G. g. gorilla & 2 & 1 & 17 & 0 & 0 & 0 & 0 & 0 & 20 \\
\hline & P.t. verus & 0 & 0 & 0 & 10 & 0 & 0 & 0 & 0 & 10 \\
\hline & P. t. troglodytes & 0 & 0 & 0 & 1 & 8 & 1 & 0 & 0 & 10 \\
\hline & $\begin{array}{l}\text { P.t. } \\
\text { schweinfurthii }\end{array}$ & 0 & 0 & 0 & 1 & 3 & 6 & 0 & 0 & 10 \\
\hline & P. paniscus & 0 & 0 & 0 & 0 & 0 & 0 & 19 & 1 & 20 \\
\hline & H. sapiens & 0 & 0 & 0 & 0 & 0 & 0 & 0 & 20 & 20 \\
\hline \multirow{8}{*}{$\begin{array}{l}\text { Cross- } \\
\text { validated }\end{array}$} & G. b. beringei & 4 & 4 & 2 & 0 & 0 & 0 & 0 & 0 & 10 \\
\hline & G. b. graueri & 3 & 6 & 1 & 0 & 0 & 0 & 0 & 0 & 10 \\
\hline & G. g. gorilla & 3 & 1 & 16 & 0 & 0 & 0 & 0 & 0 & 20 \\
\hline & P.t. verus & 0 & 0 & 0 & 9 & 0 & 1 & 0 & 0 & 10 \\
\hline & P. t. troglodytes & 0 & 0 & 0 & 2 & 6 & 2 & 0 & 0 & 10 \\
\hline & $\begin{array}{l}\text { P.t. } \\
\text { schweinfurthii }\end{array}$ & 0 & 0 & 0 & 1 & 4 & 5 & 0 & 0 & 10 \\
\hline & P. paniscus & 0 & 0 & 0 & 0 & 0 & 0 & 19 & 1 & 20 \\
\hline & H. sapiens & 0 & 0 & 0 & 0 & 0 & 0 & 1 & 19 & 20 \\
\hline
\end{tabular}

$83.6 \%$ of original grouped cases correctly classified.

$76.4 \%$ of cross-validated grouped cases correctly classified. 
Figure 1

Landmarks sited on a Pan troglodytes lower second molar (RG, Tervuren, \#29075)

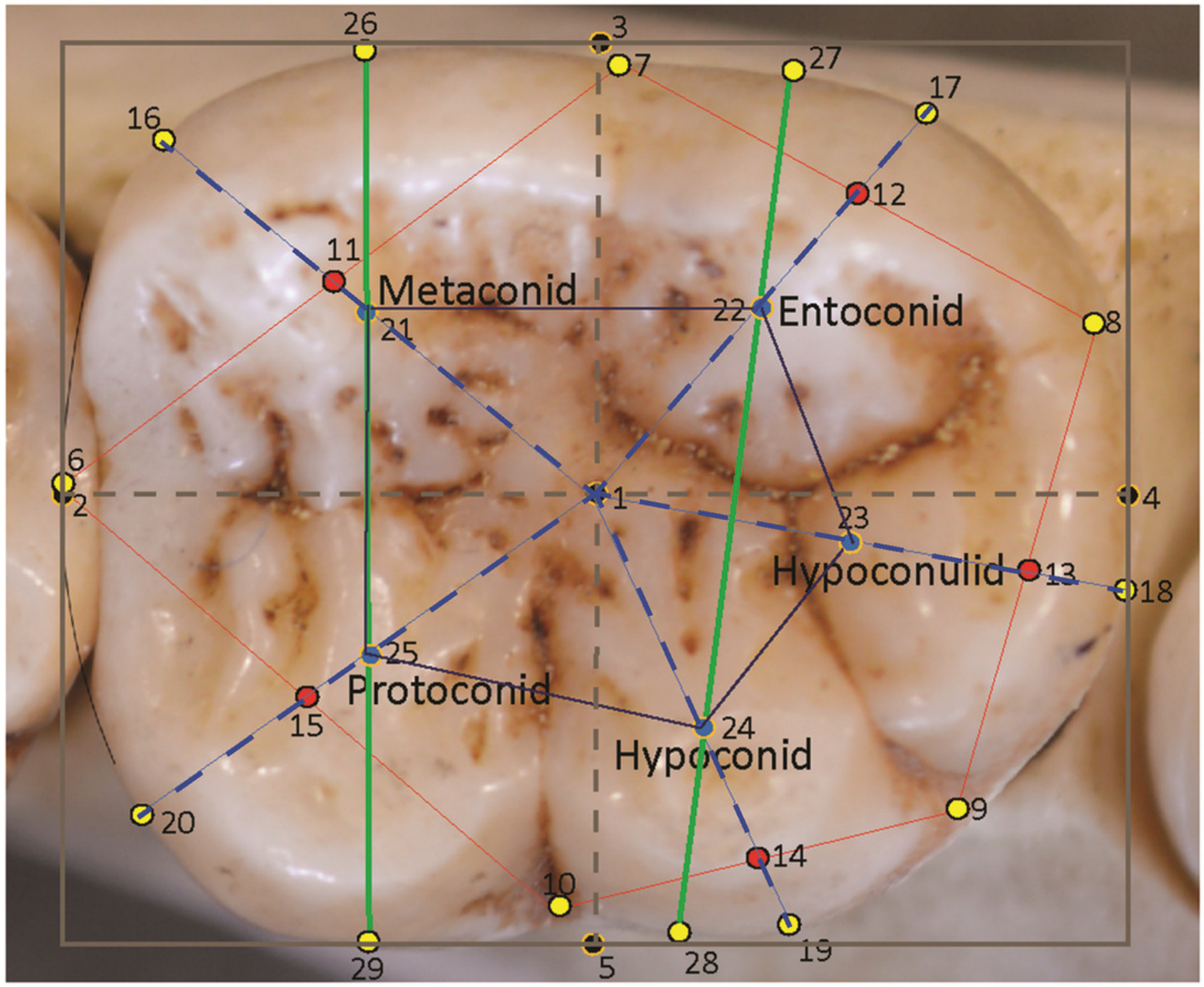


Figure 2

Landmarks on $H$. sapiens LM2 with four cusps. 


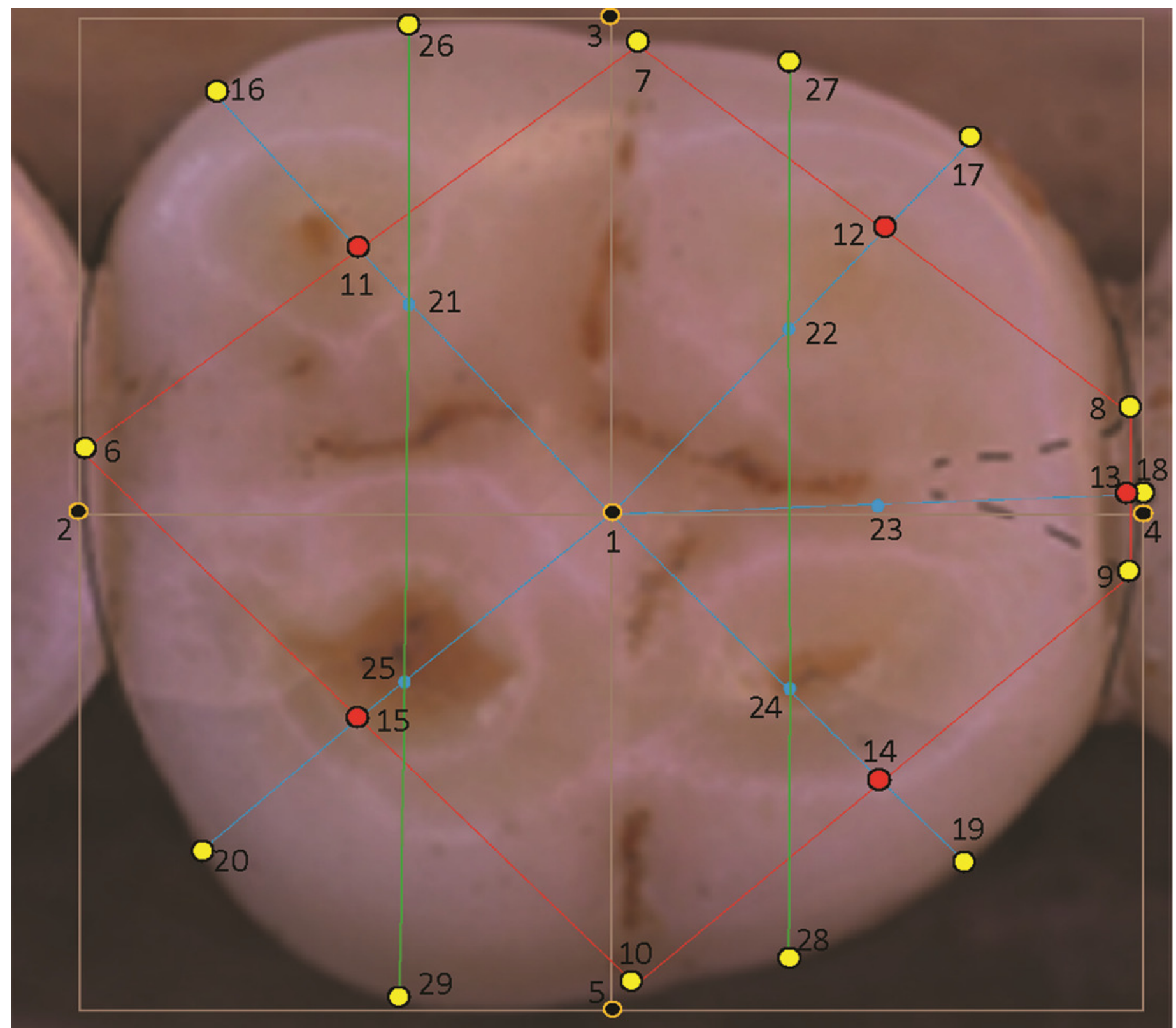


Figure 3

Homo sapiens LM2 with six cusps.

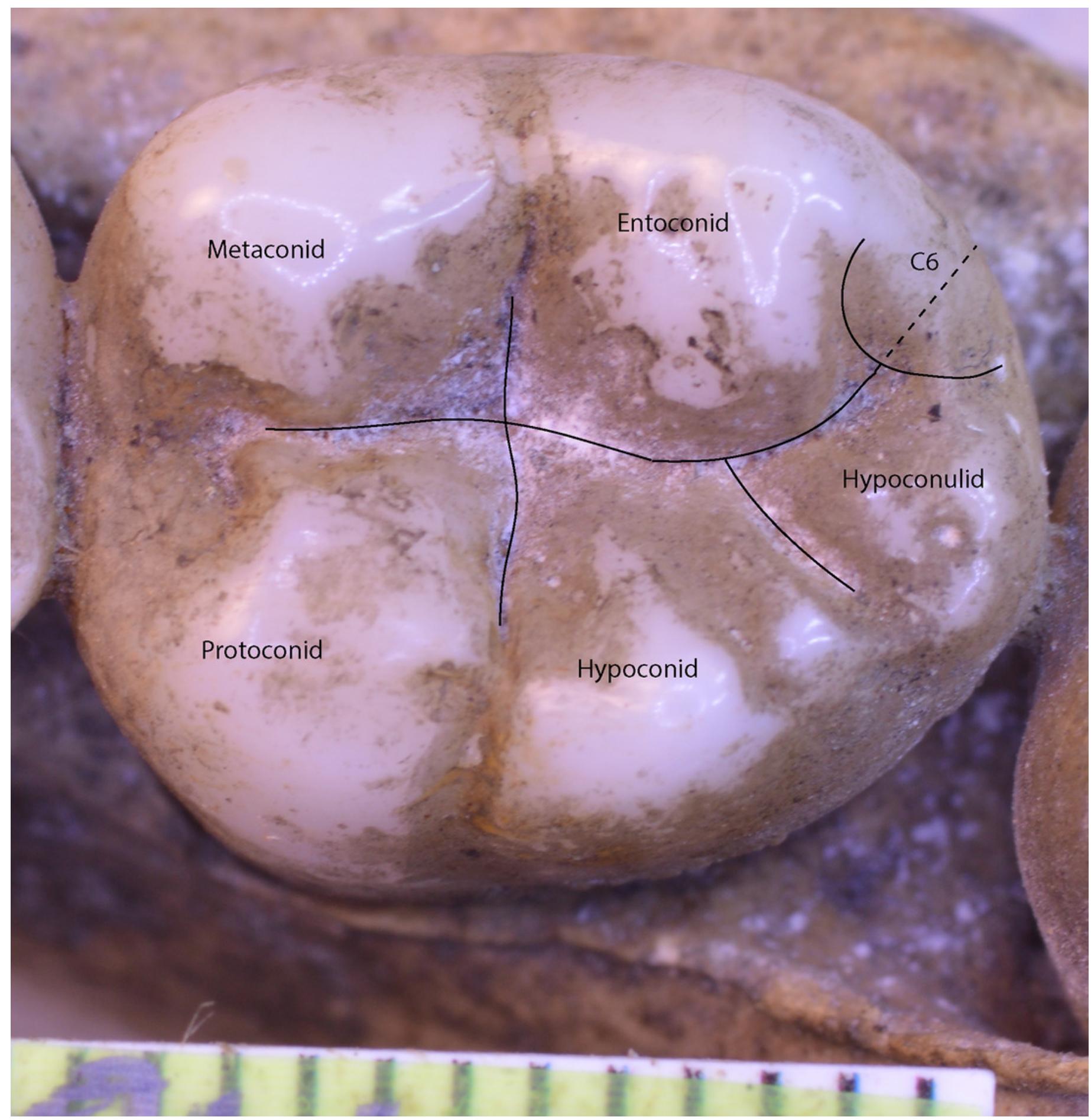


Figure 4

Raw distances (A) and angles (B) for use in DFA analyses.
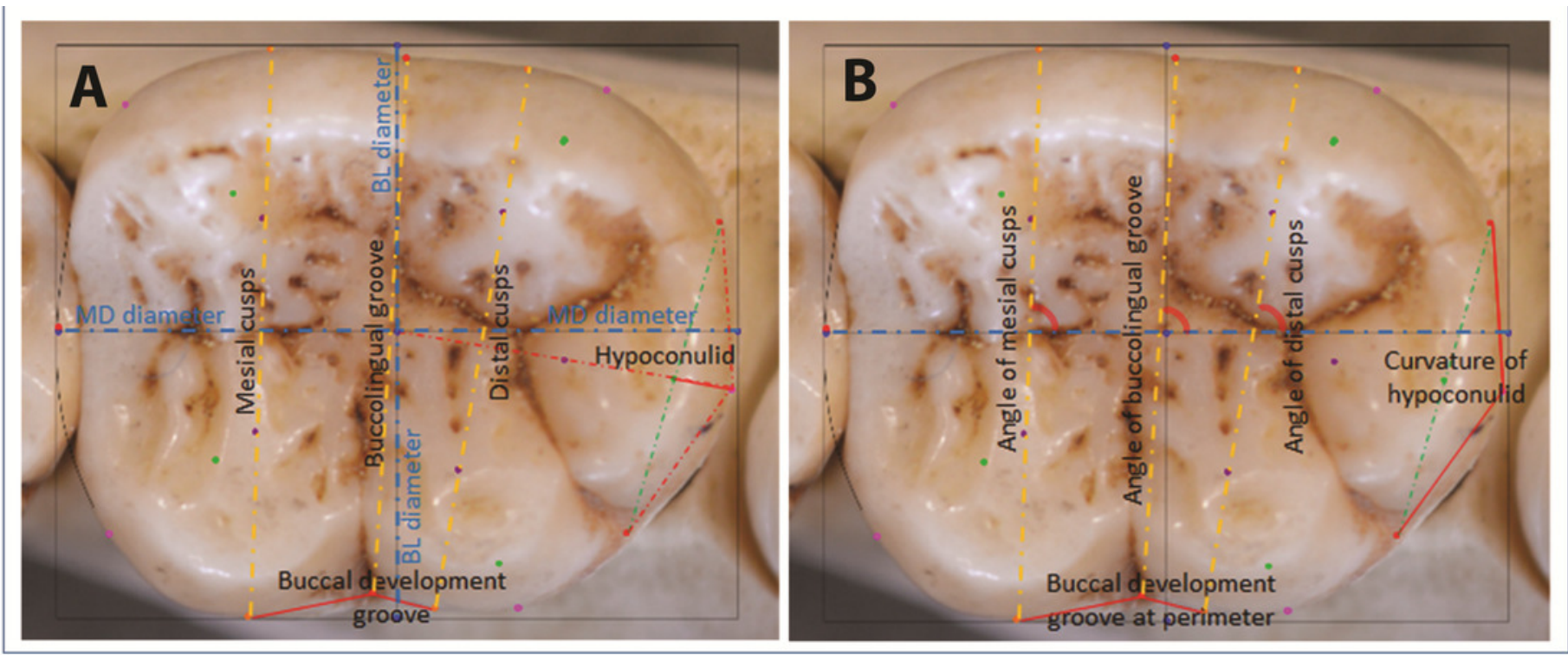


\section{Figure 5}

Principal Components analysis in shapespace (shape only) of 5 extant hominoid species.

Legend: open circles $=$ Gorilla gorilla; closed diamonds $=G$. b. beringei; X-crosses $=G . b$. graueri; $\mathrm{T}=$ Pan troglodytes troglodytes; $\mathrm{S}=P$. t. schweinfurthii; $\mathrm{V}=P$. t. verus; Targets $=P$. paniscus; Stars $=H$. sapiens. Red symbols denote females, blue symbols denote males. All wireframes depict molars with the mesial edge to the left, the distal edge to the right, the lingual edge to the top and the buccal edge to the bottom.

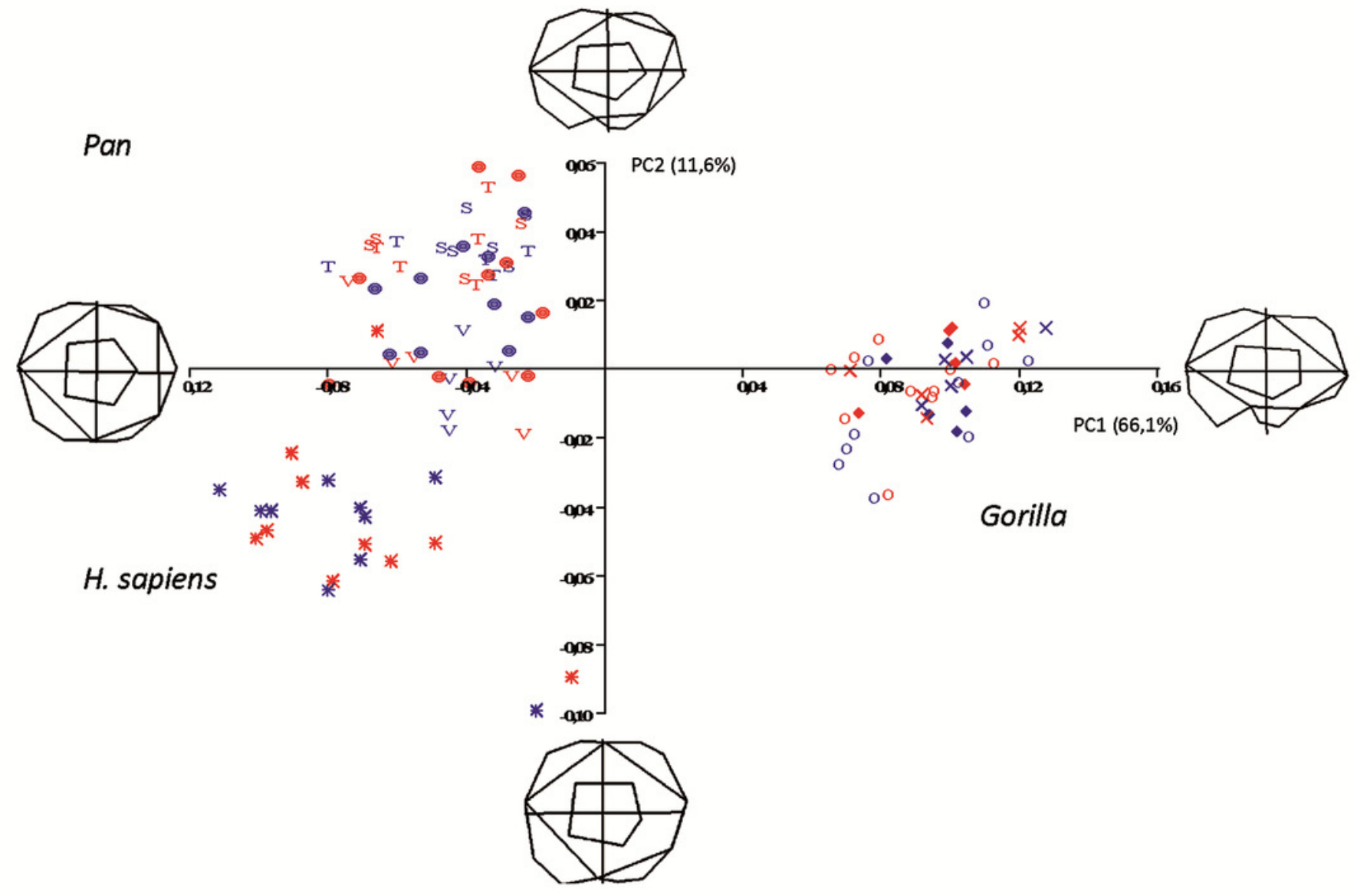




\section{Figure 6}

Principal Components analysis in formspace (shape-versus-size) of 5 extant hominoid species.

Legend: open circles $=$ Gorilla gorilla; closed diamonds $=G$. $b$. beringei; X-crosses $=G . b$. graueri; $\mathrm{T}=$ Pan troglodytes troglodytes; $\mathrm{S}=$ P. t. schweinfurthii; $\mathrm{V}=$ P. t. verus; Targets $=P$. paniscus; Stars $=H$. sapiens. Red symbols denote females, blue symbols denote males. All wireframes depict molars with the mesial edge to the left, the distal edge to the right, the lingual edge to the top and the buccal edge to the bottom.

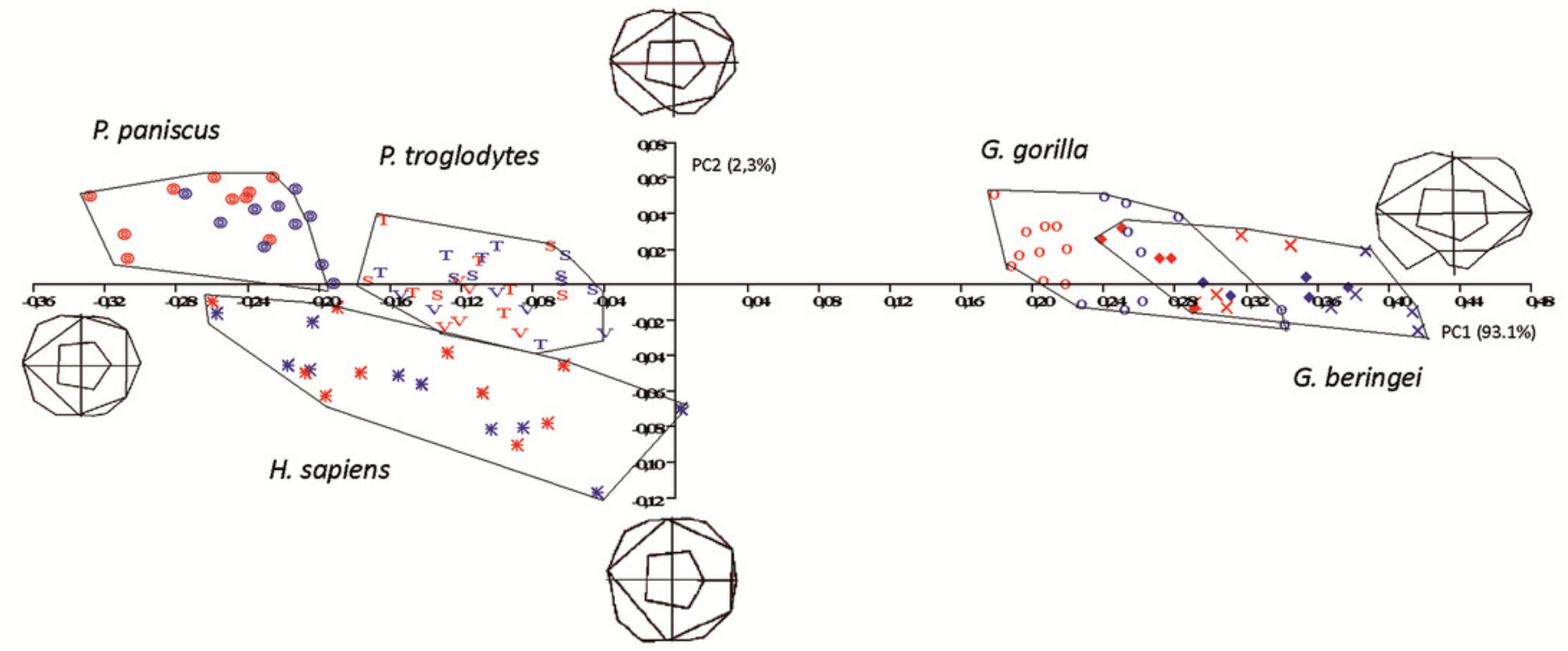


Figure 7

Convex hull plots of sample of 25 specimens chosen to match the species-subspecies groups used by Skinner et al. (2009). 


\section{Mathematical method \\ Classification accuracy $=100 \%$}

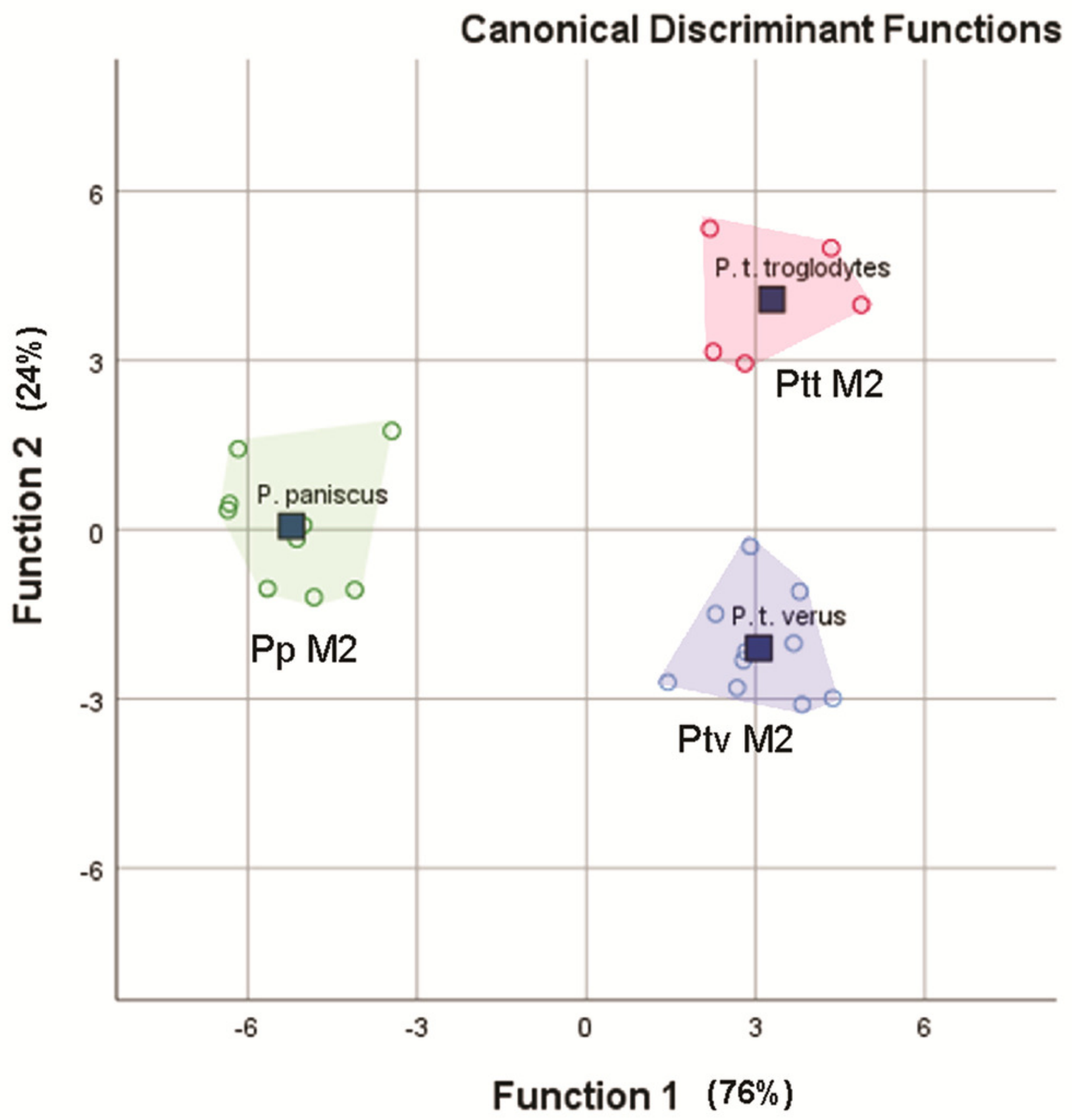

